\title{
Barotropic vorticity balance of the North Atlantic subpolar gyre in an eddy-resolving model
}

\author{
Mathieu Le Corre, Jonathan Gula, and Anne-Marie Tréguier \\ Laboratoire d'Océanographie Physique et Spatiale (LOPS), Univ. Brest, CNRS, IRD, Ifremer, IUEM, Brest, France \\ Correspondence: Mathieu Le Corre (mathieu.lecorre@univ-brest.fr)
}

Received: 16 October 2019 - Discussion started: 28 October 2019

Revised: 25 February 2020 - Accepted: 10 March 2020 - Published: 20 April 2020

\begin{abstract}
The circulation in the North Atlantic subpolar gyre is complex and strongly influenced by the topography. The gyre dynamics are traditionally understood as the result of a topographic Sverdrup balance, which corresponds to a first-order balance between the planetary vorticity advection, the bottom pressure torque, and the wind stress curl. However, these dynamics have been studied mostly with noneddy-resolving models and a crude representation of the bottom topography. Here we revisit the barotropic vorticity balance of the North Atlantic subpolar gyre using a new eddyresolving simulation (with a grid space of $\approx 2 \mathrm{~km}$ ) with topography-following vertical coordinates to better represent the mesoscale turbulence and flow-topography interactions. Our findings highlight that, locally, there is a first-order balance between the bottom pressure torque and the nonlinear terms, albeit with a high degree of cancellation between them. However, balances integrated over different regions of the gyre - shelf, slope, and interior - still highlight the important role played by nonlinearities and bottom drag curls. In particular, the Sverdrup balance cannot describe the dynamics in the interior of the gyre. The main sources of cyclonic vorticity are nonlinear terms due to eddies generated along eastern boundary currents and time-mean nonlinear terms in the northwest corner. Our results suggest that a good representation of the mesoscale activity and a good positioning of mean currents are two important conditions for a better representation of the circulation in the North Atlantic subpolar gyre.
\end{abstract}

\section{Introduction}

The North Atlantic subpolar gyre (SPG) is a key region for the meridional overturning circulation (MOC). There, the North Atlantic surface waters coming from the subtropical gyre are transformed into denser waters that flow southward and form the lower limb of the MOC. The dynamics of the currents in the SPG are a result of strong buoyancy gradients, intense surface buoyancy and wind forcings, and exchanges of waters with the Nordic Seas through overflows. Understanding these complex dynamics is essential to better understand the mechanisms that drive the variability of the MOC.

The dynamics of wind-driven oceanic gyres are traditionally understood as the result of two distinct balances for the interior of the gyre and the boundary of the gyre, where currents flow along topography. In the interior, the flow follows a Sverdrup balance, which corresponds to a first-order balance between the wind stress curl and a meridional transport in the barotropic (depth-integrated) vorticity balance. This balance has been shown to hold in the interior of subtropical gyres (Hughes and De Cuevas, 2001; Thomas et al., 2014; Yeager, 2015; Schoonover et al., 2016; Sonnewald et al., 2019; Le Bras et al., 2019). Where the currents interact with the topography, another term becomes first order in the barotropic vorticity balance: the bottom pressure torque (BPT). The BPT includes the impacts of the bottom topography on the barotropic currents and derives from the interaction of the abyssal geostrophic flow with the sloping bottom bathymetry. Works by Hughes (2000), Hughes and De Cuevas (2001), Jackson et al. (2006), and Schoonover et al. (2016) have demonstrated the prevalence of the BPT in the global barotropic vorticity balance. They have shown in particular that the BPT is the dominant term in western 
boundary currents, thus demonstrating that bottom friction and viscous effects are not required to close the vorticity budget of the gyres as hypothesized in the classical works of Stommel (1948) and Munk (1950). The SPG circulation is strongly shaped by the bottom topography. Due to weak stratification, the currents have a strong barotropic component (Van Aken, 1995; Daniault et al., 2016; Fischer et al., 2004). They are thus strongly impacted by the steep topography around the gyre. The importance of the bottom topography in driving SPG dynamics emerged quite early in the works of Luyten et al. (1985) and Wunsch (1985). The prevalence of the BPT in the SPG has also been demonstrated by Greatbatch et al. (1991), Hughes and De Cuevas (2001), Spence et al. (2012), and Yeager (2015). These studies also pointed out a failure of the flat-bottomed Sverdrup balance in this area.

The studies putting forward the importance of the BPT in the SPG have been using coarse-resolution models. But currents in the SPG are also strongly influenced by eddies, which can modify the mean flow structure (McWilliams, 2008). Models then require resolutions able to resolve these effects. Eddy-permitting resolutions have been shown to improve the characteristics of the boundary currents of the SPG, including a better position of the currents, narrower lateral extensions, and velocity amplitudes closer to observations (Treguier et al., 2005; Danek, 2019). The vertical structure of the currents is also improved with a more barotropic structure for the boundary currents around the SPG (Marzocchi, 2015). These changes, compared to coarser-resolution models, allow the inertial effects to become more important and modify the interactions with the topography. Also, at higher resolution, the viscosity is reduced and the bottom topography as well as inertial effects become prevalent, allowing the flow to better match the observations (Spence et al., 2012; Schoonover et al., 2016).

Recently, Sonnewald et al. (2019) clustered regions dominated by different barotropic vorticity balances using a global $1^{\circ} \times 1^{\circ}$ model. They retrieved the results of an SPG dominated by BPT effects, but also a part of the gyre dominated by nonlinear (NL) effects, despite the relatively coarse resolution of the model. Yeager (2015) compared results from a $1^{\circ}$ resolution model with an eddy-permitting $1 / 10^{\circ}$ resolution model and noticed an increase in the amplitude of the NL term by a factor of 3 in some locations. However, it did not significantly modify the first-order equilibrium between the wind, planetary vorticity, and BPT. The impact of the NL term becomes clearer at higher resolution. With a $1 / 20^{\circ}$ resolution simulation Wang et al. (2017) showed the importance of this term in the dynamics of recirculation gyres such as the Gulf Stream recirculation gyres, the northwestern corner, and the recirculation in the Labrador Sea (Lavender et al., 2000).

In addition to the horizontal resolution, the representation of the bottom topography has an impact on the structure of the flow. The z-level coordinates have the tendency to create flows that are too shallow compared to partial step coordinates (Pacanowski and Gnanadesikan, 1998). Terrainfollowing coordinates ( $\sigma$ level) have proven effective in representing boundary currents (Schoonover et al., 2016; Ezer, 2016). The $z$-level coordinates tend to have too much viscosity and/or diffusivity close to the topography due to the presence of vertical walls. This effect is corrected when increasing the vertical resolution or using partial steps to converge to results obtained with $\sigma$ coordinates (Ezer and Mellor, 2004).

The aim of this paper is to investigate the dynamics of the SPG by analyzing the barotropic vorticity balance in a truly eddy-resolving $\sigma$-level coordinate model. To our knowledge no study of the SPG dynamics has ever been conducted at this resolution with this kind of vertical coordinate. The switch in vertical coordinate combined with eddy-resolving resolution will allow the model to resolve more nonlinear processes and to better represent the flow-topography interactions overall, which are believed to be two essential ingredients for the circulation of the SPG. The paper is organized as follows: the simulation setup is presented in Sect. 2. The mean current characteristics and variability in the simulation are compared to observations in Sect. 3. The barotropic vorticity balance is analyzed for the full SPG in Sect. 4. The balances corresponding to the different parts of the gyre are further described in Sect. 5. To better understand what is hidden inside the nonlinear term we analyze it more in detail in Sect. 6. Conclusions are presented and discussed in Sect. 7.

\section{Model and setup}

To investigate the impact of topography on the circulation, it is essential to have a good representation of the flowtopography interactions. To do so, we use a terrain-following coordinate model: the Regional Oceanic Modelling System (ROMS; Shchepetkin and McWilliams, 2005) in its CROCO (Coastal and Regional Ocean Community) version (Debreu et al., 2012). It solves the hydrostatic primitive equations for velocity, temperature, and salinity using a full equation of state for seawater (Shchepetkin and McWilliams, 2009, 2011).

To achieve a kilometric resolution at a reasonable cost, we use a one-way nesting approach by defining two successive horizontal grids with resolutions $\Delta x \approx 6 \mathrm{~km}$ for the parent grid covering the North Atlantic Ocean (NATL) and $\Delta x \approx$ $2 \mathrm{~km}$ for the child grid covering the SPG (POLGYR). The parent North Atlantic domain is identical to the one in Renault et al. (2016). It has $1152 \times 1059$ points with a horizontal resolution of $6-7 \mathrm{~km}$. The child grid has $2000 \times 1600$ points and a horizontal resolution of $2 \mathrm{~km}$. It allows the simulation to be truly eddy-resolving in most of the area, as the first Rossby deformation radius remains below $10 \mathrm{~km}$ over most of the region (Chelton et al., 1998). The domains are shown in Fig. 1. 


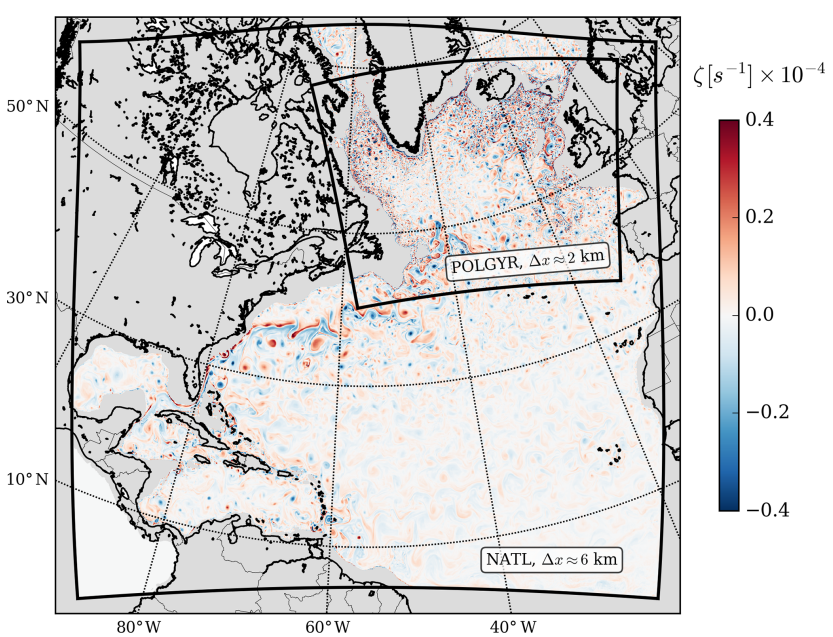

Figure 1. Snapshot of the relative vorticity at $500 \mathrm{~m}$ of depth in the North Atlantic in the NATL simulation. The NATL grid $(\Delta x \approx 6 \mathrm{~km}$ ) covers most the North Atlantic, and the POLGYR grid (smaller rectangle, $\Delta x \approx 2 \mathrm{~km}$ ) covers the subpolar gyre.

The bathymetry for both domains is constructed from the SRTM30 PLUS dataset (available online at http:// topex.ucsd.edu/WWW_html/srtm30_plus.html, last access: March 2020) based on the 1 min (Sandwell and Smith, 1997) global dataset and higher-resolution data where available. A Gaussian smoothing kernel with a width 4 times the topographic grid spacing is used to avoid aliasing whenever the topographic data are available at higher resolution than the computational grid and to ensure the smoothness of the topography at the grid scale. Also, to avoid pressure gradient errors induced by terrain-following coordinates in shallow regions with steep bathymetric slopes (Beckmann and Haidvogel, 1993), we locally smooth the bottom topography $h$ to ensure that the steepness of the topography does not exceed a factor $r=0.2$, where the local $r$ factor is defined in the $x$ and $y$ directions by $r_{x}=\frac{h(i, j)-h(i-1, j)}{h(i, j)+h(i-1, j)}$ and $r_{y}=\frac{h(i, j)-h(i, j-1)}{h(i, j)+h(i, j-1)}$, with $(i, j)$ representing the grid index.

Initial and lateral boundary data for the largest domain are taken from the Simple Ocean Data Assimilation (SODA; Carton and Giese, 2008). The NATL simulation is run from 1 January 1999 to 31 December 2008. It is spun up for 2 years, and the following 8 years are used to generate boundary conditions for the child grid. Our focus is the barotropic vorticity dynamics, characterized by timescales on the order of months, such that a year of spin-up is sufficient for the kinetic energy (both for barotropic and baroclinic modes) to reach a state of quasi-equilibrium in POLGYR (not shown). The study is carried on the 7 remaining years between 2002 and 2008. The surface forcings are daily ERA-Interim data for the parent grid and the child grid.

The North Atlantic and subpolar gyre simulations have 50 and 80 vertical levels, respectively. Vertical levels are stretched at the surface and bottom (Lemarié et al., 2012) to have a better representation of the surface layer dynamics at the top and flow-topography interactions at the bottom. The depth of the transition between flat $z$ levels and terrain-following $\sigma$ levels is $h_{\text {cline }}=300 \mathrm{~m}$. The two parameters controlling the bottom and surface refinement of the grid are $\sigma_{\mathrm{b}}=2$ and $\sigma_{\mathrm{s}}=7$ for the parent grid and $\sigma_{\mathrm{b}}=3$ and $\sigma_{\mathrm{s}}=6$ for the child grid, corresponding to strongly stretched levels at the surface and bottom (Fig. 2).

The vertical mixing of tracers and momentum is done by a $k-\epsilon$ model (GLS; Umlauf and Burchard, 2003). The effect of bottom friction is parameterized through a logarithmic law of the wall with a roughness length $Z_{0}=0.01 \mathrm{~m}$. We use no explicit horizontal viscosity or diffusivity and rely on thirdorder upwind-biased advection schemes, which include an implicit hyperdiffusivity at the grid scale.

\section{Mean currents and variability}

\subsection{Mean circulation}

Before investigating what is driving the SPG dynamics, we first need to validate the mean circulation in our simulations. Mean velocities from the two simulations (NATL and POLGYR) at the surface and $1000 \mathrm{~m}$ of depth are shown in Fig. 3. We present at the bottom of Fig. 3e and $\mathrm{f}$ the amplitudes of the currents from the NOAA drifter climatology (Laurindo et al., 2017) at the surface and from the Argo-based ANDRO dataset at $1000 \mathrm{~m}$ of depth (Ollitrault and Rannou, 2013; Lebedev et al., 2007). The ANDRO data have been binned on a $0.25^{\circ} \times 0.25^{\circ}$ grid, and cells with fewer than 10 data points have been removed.

The North Atlantic Current (NAC) represents a boundary between the subtropical and the subpolar gyres. Oceanic models have difficulties in reproducing its dynamics, particularly its northern extension known as the northwest corner (Bryan et al., 2007; Hecht and Smith, 2008; Drews et al., 2015), which is centered at $50^{\circ} \mathrm{N}, 48^{\circ} \mathrm{W}$ (Lazier, 1994). These difficulties lead to the apparition of the so-called "cold-bias", which can reach up to $10^{\circ} \mathrm{C}$ (Griffies et al., 2009; Drews et al., 2015) and which plays a role in Atlantic low-frequency variability (Drews and Greatbatch, 2017). The northwest corner is well reproduced in our simulations, and the temperature bias at this location is less than a degree.

After turning eastward, the NAC splits into three branches, which are strongly constrained by topography (Bower, 2008). They cross the Mid-Atlantic Ridge (MAR) through three deep fracture zones: the Charlie-Gibbs Fracture Zone $\left(\mathrm{CGFZ} ; 52.5^{\circ} \mathrm{N}\right)$, the Faraday Fracture Zone $\left(50^{\circ} \mathrm{N}\right)$, and the Maxwell Fracture Zone ( $48^{\circ} \mathrm{N}$ ) (Bower et al., 2002). In both surface and $1000 \mathrm{~m}$ observations (Fig. 3e, f), the northern branch of the NAC is more intense and corresponds to the main pathway across the MAR. The three branches are well represented in the simulations with, at the surface, an overestimation of the southern branch and an underestima- 

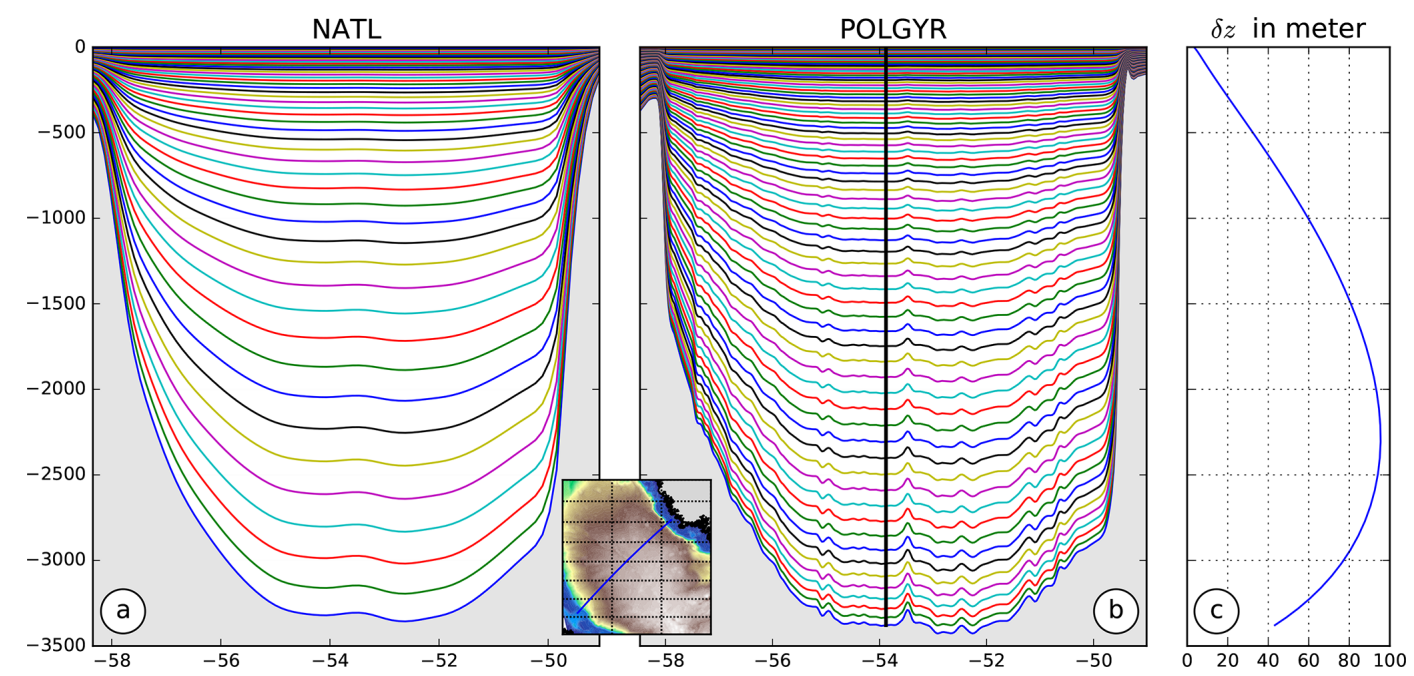

Figure 2. Depths of the model vertical $\sigma$ levels along a section in the Labrador Sea for (a) the $6 \mathrm{~km}$ simulation (NATL) and (b) the $2 \mathrm{~km}$ simulation (POLGYR). (c) The vertical grid spacing with depth along the black line shown in (b).

tion of the northern branch. At depth, ANDRO data depict an intense branch crossing the MAR at the CGFZ, while the amplitude of the two southern branches is smaller. This feature might be related to the Labrador Sea water passing into the eastern basin through the CGFZ in this depth range, while in the Faraday and Maxwell fracture zones the flow is more surface-intensified. The circulation in POLGYR is closer to the observations, with a better representation of the flow in the CGFZ at $1000 \mathrm{~m}$.

After crossing the MAR, the three branches head north, with the two northern ones feeding the interior of the Iceland Basin and the Rockall Trough (RT) (Daniault et al., 2016). The water coming from the Maxwell Fracture Zone recirculates southward in the West European Basin (Paillet and Mercier, 1997). As most of the models (Treguier et al., 2005; Deshayes et al., 2007), NATL and POLGYR are consistent with observations for the circulation in the eastern basin, with a good positioning of the two main branches respectively passing in the Maury Channel (the deepest part of the Iceland Basin west of Hatton Bank) and the RT.

A deep permanent anticyclonic eddy is found in Rockall Trough (Fischer et al., 2018; Smilenova et al., 2020; Le Corre et al., 2019). This structure is detectable in the ANDRO dataset around $55^{\circ} \mathrm{N}, 12^{\circ} \mathrm{W}$ (Fig. 3f). It is not present in NATL, while it appears in POLGYR, albeit with velocities that are too intense. In NATL at depth, there is a strong southward flow in the western part of the RT due to the wrong representation of the Faroe Bank Channel. As the topography is strongly smoothed, the channel is not properly represented and does not allow the dense water coming from the Nordic Seas to pass through it and feed the Iceland-Scotland Overflow Water properly (Hansen et al., 2016; Kanzow and Zenk, 2014). Thus, the water is recirculating in the western part of the RT, creating a spurious pattern (Fig. $3 b$ ). The problem is solved by increasing the horizontal resolution and improving the representation of the topography, which corresponds to a wider opening of the channel and allows for a more realistic circulation in the RT.

Further north, part of the flow continues to the Nordic Seas (Rossby and Flagg, 2012), while the other part follows the Reykjanes Ridge (RR). A common bias in models east of the RR is a southward flow that is too intense at the surface (Treguier et al., 2005). This bias is present in NATL but disappears at higher resolution in POLGYR, which is closer to the circulation observed by the drifters. On the western side of the RR the signal of the strong northward Irminger Current visible in observations is well resolved by the simulations (Fig. 3).

At $1000 \mathrm{~m}$ of depth, Argo floats reveal a continuous current following the eastern RR flank until reaching the CGFZ, with some of the flow crossing the ridge north of $57.3^{\circ} \mathrm{N}$ and some crossing at the Bight Fracture Zone $\left(56-57^{\circ} \mathrm{N}\right)$. This is consistent with the results from Petit et al. (2018), who observed that water at this depth (their layer 3) was more likely to cross the ridge north of $56^{\circ} \mathrm{N}$. This southwestward flow is present in our simulations, with velocity amplitudes that are too intense in NATL but realistic amplitudes at higher resolution in POLGYR. In both cases, we clearly see the flow crossing the ridge north of $56^{\circ} \mathrm{N}$. On the western side of the $\mathrm{RR}$, the velocity in the simulations is too strong compared to observations. The mean subpolar gyre intensity in the model (Fig. 4), computed as the cumulative transport from Iceland to $53.15^{\circ} \mathrm{N}$ along the crest of the RR, is equal to $-25 \mathrm{~Sv}$ and compares well with the $-21.9 \pm 2.5 \mathrm{~Sv}$ monthly average in Petit et al. (2018).

Numerous recirculations are present in the SPG, many of them occurring near the intense boundary currents along Greenland and around the Labrador Sea (Reverdin, 2003; 

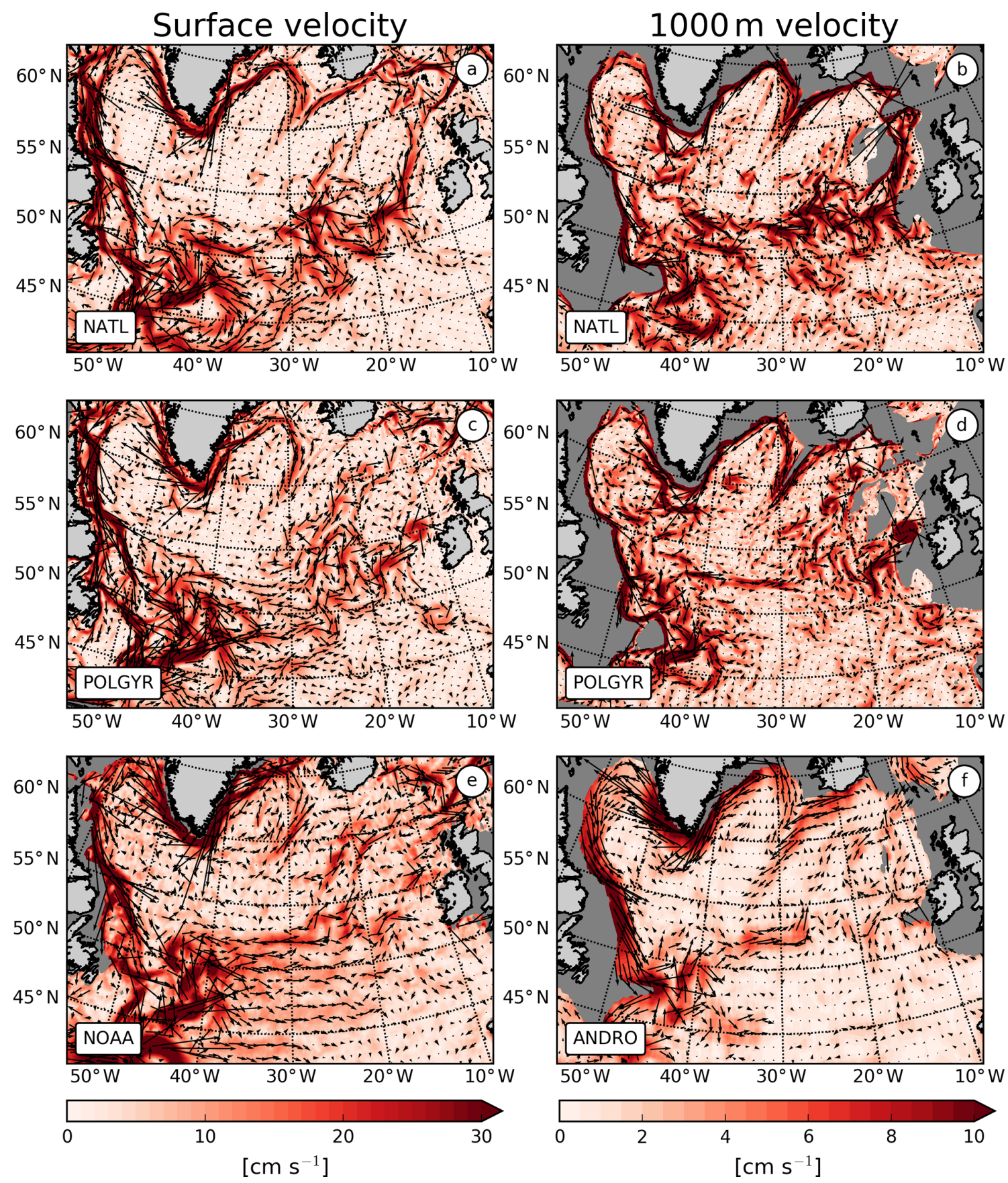

Figure 3. Mean velocity averaged over 2002-2008 at the surface (a, c, e) and $1000 \mathrm{~m}$ (b, d, f) in NATL (a, b), POLGYR (c, d) and observations, and NOAA drifters and $\operatorname{ANDRO}(\mathbf{e}, \mathbf{f})$.

Flatau et al., 2003; Cuny et al., 2002). Recirculation cells are present in the Labrador Sea (Lavender et al., 2000; Cuny et al., 2002) and extend to the Irminger Basin (Holliday et al., 2009). Käse et al. (2001) and Spall and Pickart (2003) suggested that both the topography and the wind drive these features, which are stable in time (Palter et al., 2016). More recently, Wang et al. (2017) showed the importance of the mean flow advection in these circulations. Some models are unable to correctly reproduce the recirculation cells, especially the one in the center of the Labrador Sea (Treguier et al., 2005). In our case, this recirculation is well represented (Fig. 3a, b, $\mathrm{c}, \mathrm{d})$. The counter current flows offshore of the Labrador continental slope, with a northward extension at $60^{\circ} \mathrm{N}$, which matches observations from Lavender et al. (2005). At the tip of Greenland, this counter current separates in two to form a branch flowing inside the Irminger Basin, while the other 


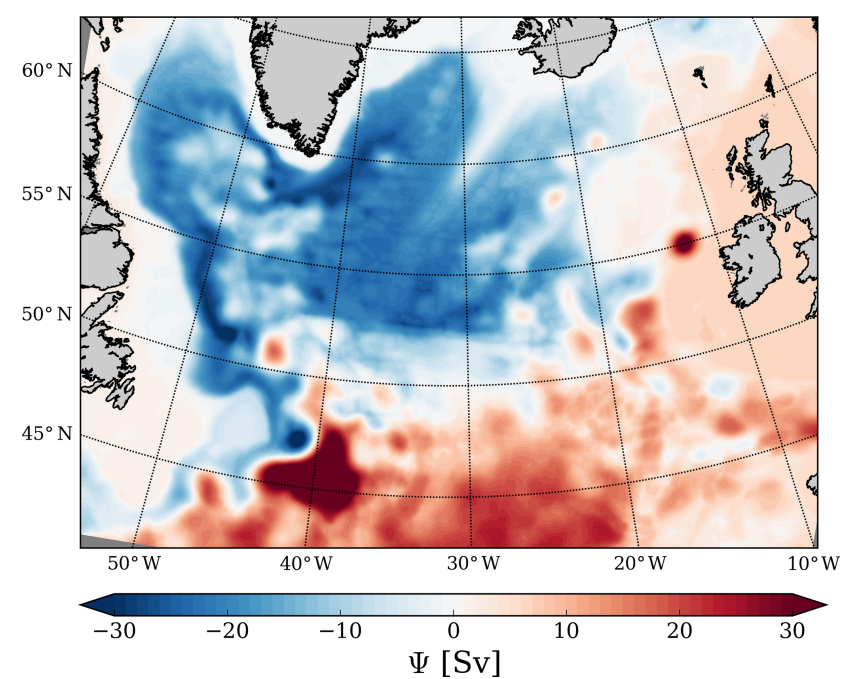

Figure 4. Time-mean barotropic stream function over 2002-2008.

branch is redirected southward. This second branch is relatively intense in our simulation but is also present in ANDRO data (Fischer et al., 2018, their Figs. 3 and 5a).

\subsection{The mesoscale activity}

Mesoscale activity plays a big role in redistributing water mass properties in the SPG (Brandt, 2004; de Jong et al., 2016; Zhao et al., 2018). The presence of mesoscale eddies can be inferred by their signatures on the eddy kinetic energy (EKE). From the surface EKE signal extracted from NOAA drifters on a $0.25^{\circ} \times 0.25^{\circ}$ grid (Fig. 5e), we retrieve the main hot spots described by Flatau et al. (2003) in the SPG: the Labrador Sea and the Irminger and Iceland basins. Those signals are mainly due to the generation of mesoscale eddies through baroclinic and barotropic instabilities of the boundary currents.

EKE amplitudes in the NATL simulation are weaker than in observations, but the eddy activity is enhanced when the resolution is increased. The POLGYR simulation displays similar EKE patterns as observational data in every basin (Labrador, Irminger, and Iceland), with close amplitudes over most of the SPG. The EKE patterns corresponding to the generation of Irminger rings have higher magnitudes in POLGYR than in the NOAA drifter data.

A way to quantify the mesoscale activity at depth is to look at the vertical isopycnal displacements. When referenced to a mean, it represents the eddy available potential energy (EAPE) or the amount of energy stored in the potential energy reservoir due to mesoscale activity (Lorenz, 1955). This quantity is a proxy for the baroclinic activity in the interior of the ocean and is computed following the Roullet et al. (2014) formulation:

$\mathrm{EAPE}=-\frac{g}{2 \rho_{0}}\left\langle z^{\prime} \rho^{\prime}\right\rangle$, where $z^{\prime}$ is the vertical isopycnal displacement, $\rho^{\prime}$ is the density anomaly associated with this displacement, and $\langle\bullet\rangle$ is the time average. We compare EAPE from the simulations with the atlas of Roullet et al. (2014) constructed from Argo data (Fig. 5f). The atlas presented here is an update of the original product, which uses virtual density instead of potential density and includes more recent data up to July 2015. In NATL (at $6 \mathrm{~km}$ resolution) most of the baroclinic activity already seems well resolved. However, observations highlight an EAPE maximum on the western flank of the RR that is missing in NATL but appears only in POLGYR (at $2 \mathrm{~km}$ resolution). In contrast, strong patches of EAPE are visible along the boundary currents of the western half of the SPG in NATL but are not visible in observations. Interestingly, these patterns weaken in POLGYR, potentially pointing to a change in the vertical structure of the currents at higher resolution. Another factor to take into consideration is the lack of Argo measurements close to the boundaries, which might cause an underestimation of EAPE at these locations.

\section{Vorticity balance of the subpolar gyre at high resolution}

\subsection{An overall view of the subpolar gyre vorticity balance}

Two barotropic vorticity equations can be obtained depending on the choice of vertically averaging or integrating the momentum equations before cross-differentiating them. While the former helps to quantify the barotropic flow across the $f / h$ contour, the latter defines the main barotropic forcing on the flow. Our main focus being to define the main forcing of the SPG, the last definition will be used in the following and can be written as (Gula et al., 2015)

$$
\begin{aligned}
\underbrace{\frac{\partial \Omega}{\partial t}}_{\text {rate }} & =-\underbrace{\nabla \cdot(f \overline{\boldsymbol{u}})}_{\text {planet. vort. adv }}+\underbrace{\frac{J\left(P_{\mathrm{b}}, h\right)}{\rho_{0}}}_{\text {BPT }}+\underbrace{\boldsymbol{k} \cdot \nabla \times \frac{\boldsymbol{\tau}_{\text {wind }}}{\rho_{0}}}_{\text {wind curl }} \\
& -\underbrace{\boldsymbol{k} \cdot \boldsymbol{\nabla} \times \frac{\boldsymbol{\tau}_{\text {bot }}}{\rho_{0}}}_{\text {BDC }}+\underbrace{D_{\Sigma}}_{\text {horiz. diffusion }}+\underbrace{A_{\Sigma}}_{\text {NLA }},
\end{aligned}
$$

where the vorticity $\Omega$ is the curl of the vertically integrated components of the velocity between the bottom and the surface: $\Omega=\boldsymbol{k} \cdot \nabla \times \overline{\boldsymbol{u}}$, with $\boldsymbol{u}=(u, v)$ the velocities in the $(x, y)$ direction. The overbar defines a vertically integrated quantity:

$\bar{u}=\int_{-h}^{\eta} u \mathrm{~d} z$,

with $\eta(x, y, t)$ the free surface height and $h(x, y)$ the topography. It is possible to decompose the planetary vorticity advection $-\nabla \cdot(f \bar{u})=-\beta V-f \frac{\partial \eta}{\partial t} \approx-\beta V$, with $V$ the vertically integrated meridional component of velocity, if we 

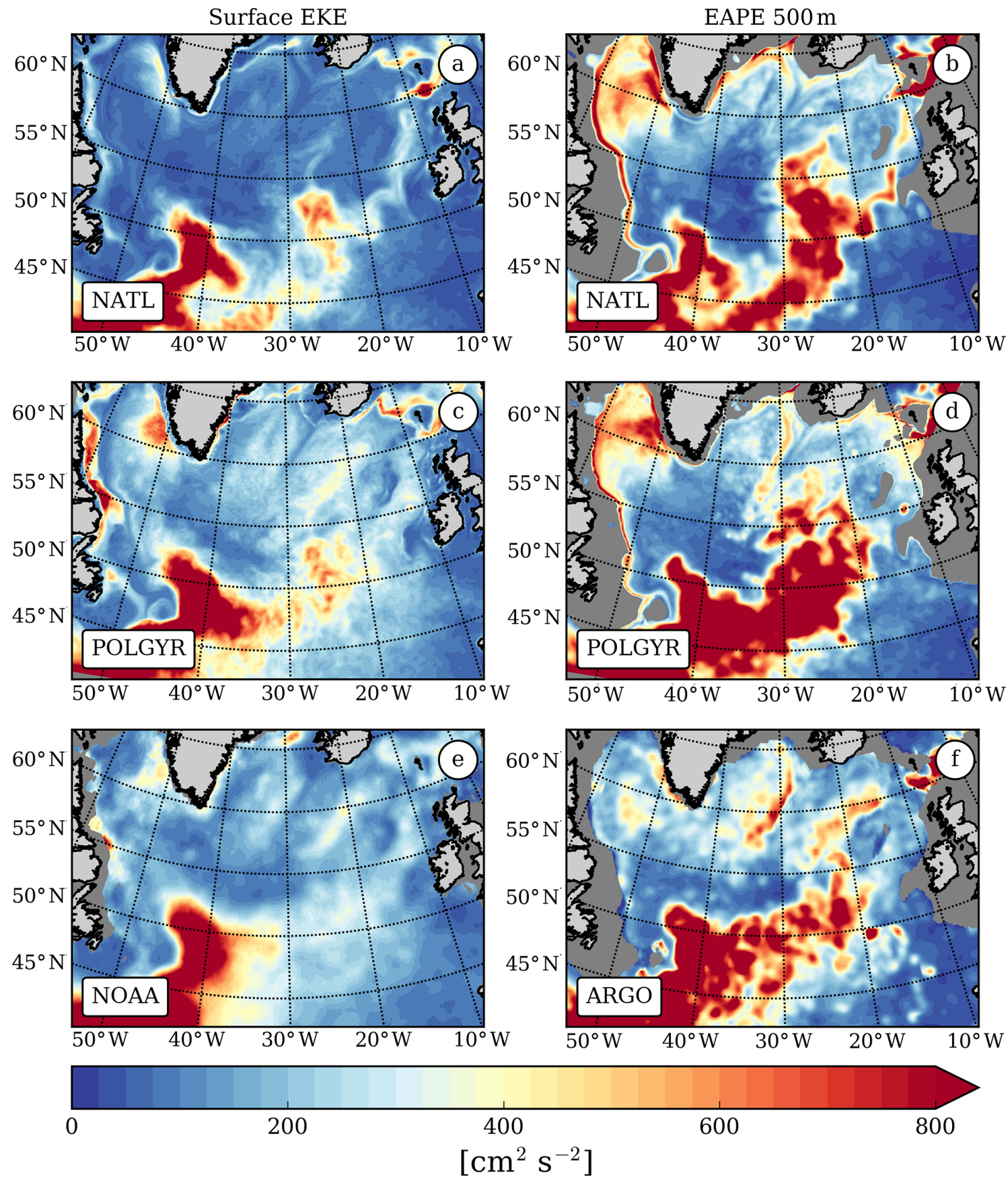

Figure 5. Mean surface eddy kinetic energy (a, c, e) and mean eddy available potential energy between 2002 and 2008 (b, d, f) in NATL (a, b) and POLGYR (c, d). These are compared with results from the NOAA database (e) and the EAPE atlas from Roullet et al. (2014) (f).

consider a mean over a long enough time period such that $\frac{\partial \eta}{\partial t} \approx 0$.

The nonlinear term can be written as

$A_{\Sigma}=-\frac{\partial^{2}(\overline{v v}-\overline{u u})}{\partial x \partial y}-\frac{\partial^{2} \overline{u v}}{\partial x \partial x}+\frac{\partial^{2} \overline{u v}}{\partial y \partial y}$.

The expression for $A_{\Sigma}$ is similar to the one shown in Schoonover et al. (2016) (their Eq. 2), but in our case, the integration between $-h$ and $\eta$ allows their last term to cancel out with a residue from the inversion of the time derivative and the vertical integral in the rate term. The bottom pressure torque $J\left(P_{\mathrm{b}}, h\right)$ is the Jacobian of the bottom pressure and the depth of the topography. It encompasses the effects of the varying topography on the flow and is known to play a key role in the barotropic vorticity balance of the SPG. In an idealized case of a geostrophic current flowing along 
a topography in free-slip condition, the BPT can be written $\frac{J\left(P_{\mathrm{b}}, h\right)}{\rho_{0}}=f u_{\mathrm{b}} \cdot \nabla h$, where $\rho_{0}$ is the mean reference density and the subscript " $b$ " denotes a field at the bottom. Given the kinematic condition at the bottom, $-u_{\mathrm{b}} \cdot \nabla h=w_{\mathrm{b}}$, the BPT can be written $\frac{J\left(P_{\mathrm{b}}, h\right)}{\rho_{0}}=-f w_{\mathrm{b}}$, which highlights the relation between the $\stackrel{\rho_{0}}{\text { BPT }}$ and vortex stretching when the flow crosses an isobath.

The barotropic vorticity terms have already been computed for the North Atlantic using different models (Ocean Circulation and Climate Advanced Modelling - OCCAM, University of Victoria Earth System Climate Model - UVic, Estimating the Circulation and Climate of the Ocean ECCO, Parallel Ocean Program - POP) at different resolutions $\left(0.25^{\circ}\right.$, Hughes and De Cuevas, $2001 ; 0.2^{\circ} \times 0.4^{\circ}$, Spence et al., 2012; $1^{\circ}$, Sonnewald et al., 2019; $0.1^{\circ}$, Yeager, 2015). The major result is that the barotropic vorticity balance in the subtropical and subpolar gyres is at first order a balance between $\beta V, \nabla \times \frac{\tau_{\text {wind }}}{\rho_{0}}$, and $\frac{J\left(P_{\mathrm{b}}, h\right)}{\rho_{0}}$.

In the subtropical gyre, the barotropic vorticity balance is close to a Sverdrup balance away from the boundaries $(\beta V \approx$ $\left.\nabla \times \frac{\tau_{\text {wind }}}{\rho_{0}}\right)$, while the closure of the northward branch of the gyre at the western boundary is done primarily through BPT $\left(\beta V \approx \frac{J\left(P_{\mathrm{b}}, h\right)}{\rho_{0}}\right)$ (Schoonover et al., 2016).

The barotropic vorticity balance in the SPG is slightly more complex due to the strong impact of the topography. Along the northern and western boundaries of the SPG, the first-order balance is between meridional advection and BPT $\left(\beta V \approx \frac{J\left(P_{\mathrm{b}}, h\right)}{\rho_{0}}\right)$ (e.g., Hughes and De Cuevas, 2001, their Fig. 4; Yeager, 2015, their Fig. 1), with a significant impact of the wind only in the northern part of the gyre along the Greenland coast. When the resolution of the model is increased from 1 to $0.1^{\circ}$ in Yeager (2015), the main balances stay qualitatively similar, showing a modest effect of the eddies. Using a shallow water model with higher resolution $\left(1 / 20^{\circ}\right)$, Wang et al. (2017) illustrate the importance of the NL term in the dynamics of specific regions such as the Gulf Stream and the Labrador recirculation in the SPG. The viscous torque decreases in the boundary currents due to the lower viscosity of their model.

\subsection{Spatial scales of the vorticity balance}

In our simulations, the BPT balances the nonlinear term at leading order everywhere in the domain (Fig. 6). This is qualitatively different from the vorticity balances shown in Yeager (2015), but it is similar to the results of Gula et al. (2015) in the Gulf Stream region with the same ocean model and a similar horizontal resolution. This highlights the fact that locally the flow is able to follow isobaths due to an equilibrium between the NL term (making the flow cross isobaths) and the bottom pressure anomaly.

Both terms exhibit small scales related to topographic features but with a high degree of cancellation between them. The sum of the BPT and NL terms (Fig. 6c) is often an order of magnitude smaller than the amplitude of the terms considered individually and exhibits patterns and amplitudes matching the advection of planetary vorticity. This cancellation is also clear in Wang et al. (2017), their Fig. 3, where the transport driven by mean flow advection balances the one driven by the BPT, both having amplitudes larger than the wind-stress-curl-driven transport.

To facilitate the interpretation of maps of NL and BPT terms, the impact of small topographic scales has to be reduced by smoothing with a large enough length scale. NL terms in particular are expected to be smoothed out on scales larger than 1-2 (Hughes and De Cuevas, 2001). Figure 7 shows all terms smoothed with a Gaussian kernel of $1^{\circ}$ radius. Even with such smoothing, the BPT and NL terms are still significantly larger than the corresponding results from the $0.1^{\circ}$ simulation of Yeager (2015). However, their sum $\frac{J\left(P_{\mathrm{b}}, h\right)}{\rho_{0}}+A_{\Sigma}$ (Fig. 7f) is of the same order of magnitude as the $\beta V$ (Fig. 7a) and the bottom drag curl (BDC; Fig. 7e). More precisely, the $\beta V$ term balances the sum $\frac{J\left(P_{\mathrm{b}}, h\right)}{\rho_{0}}+A_{\Sigma}$ over most of the domain, while the BDC locally plays a role in the shallow areas.

The curl of the wind stress in POLGYR has the same pattern and amplitude as in Yeager (2015). It is mostly positive, with the strongest signal on the eastern coast of Greenland. The amplitude of the $\beta V$ term is slightly stronger in our model than in coarser-resolution simulations. In the simulations of Hughes and De Cuevas (2001) and Yeager (2015), the patterns of the $\beta V$ term seem to indicate much wider currents. Here, the patterns correspond to thinner and more intense currents, closely following the continental slopes, in agreement with the observations.

In our simulations, the amplitude of the viscous torque, due to the implicit horizontal viscosity of the model $\left(D_{\Sigma}\right)$, is very small compared with the amplitude of the BDC. This is opposite to the results of the $0.1^{\circ}$ POP simulation of Yeager (2015). In fact, their viscous term is qualitatively similar in pattern to the bottom drag curl in our simulation. The boundary conditions near the topography are quite different in the two models due to the different vertical coordinates. The $z$ level coordinates have vertical walls between each level, with parameterized lateral viscosity, which explains the pattern in Yeager (2015). The $\sigma$-level coordinates have no lateral boundary conditions, and friction on the topographic slopes is only parameterized as a bottom drag. The amplitude of the $\mathrm{BDC}$ is, however, stronger in our simulation than the viscous term in Yeager (2015) and seems to play an important role in balancing the BPT and $\beta V$ terms over the shelf and on the upper part of the continental slope along the northern and western boundaries of the gyre.

\subsection{Link between barotropic vorticity balance and bottom velocities}

As explained previously, the bottom pressure torque $J\left(P_{\mathrm{b}}, h\right)$ can be identified with a bottom vortex stretching term: 


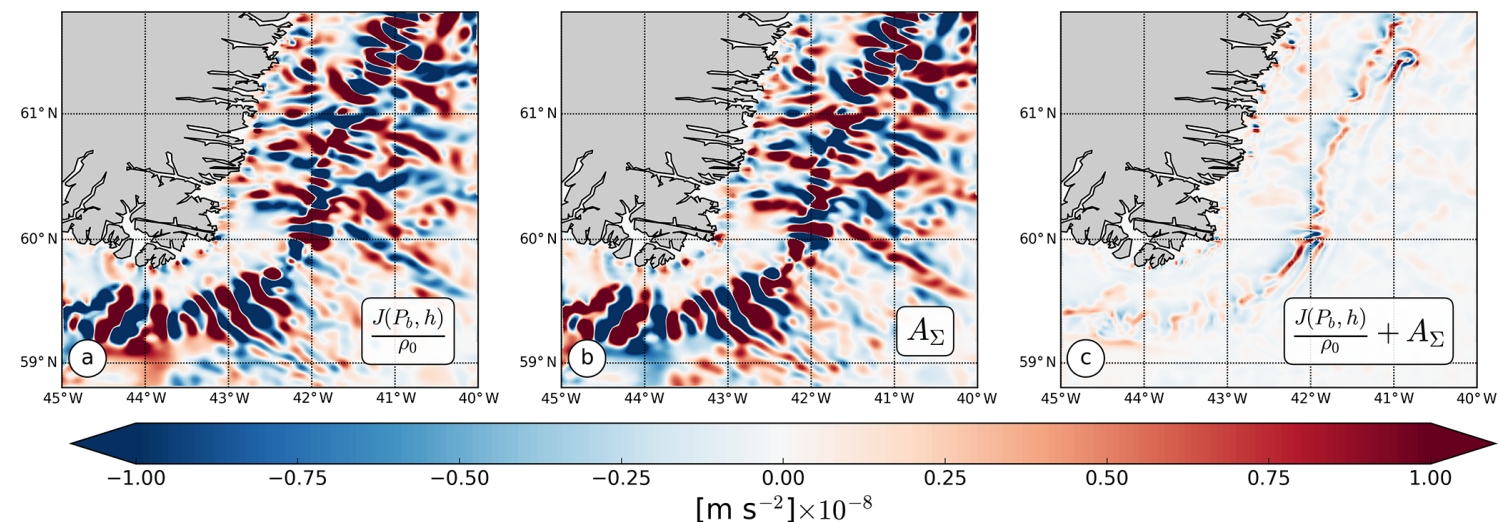

Figure 6. Time-mean (a) bottom pressure torque, (b) nonlinear terms, and (c) the sum of the two for eastern Greenland in the $2 \mathrm{~km}$ North Atlantic subpolar gyre simulation.
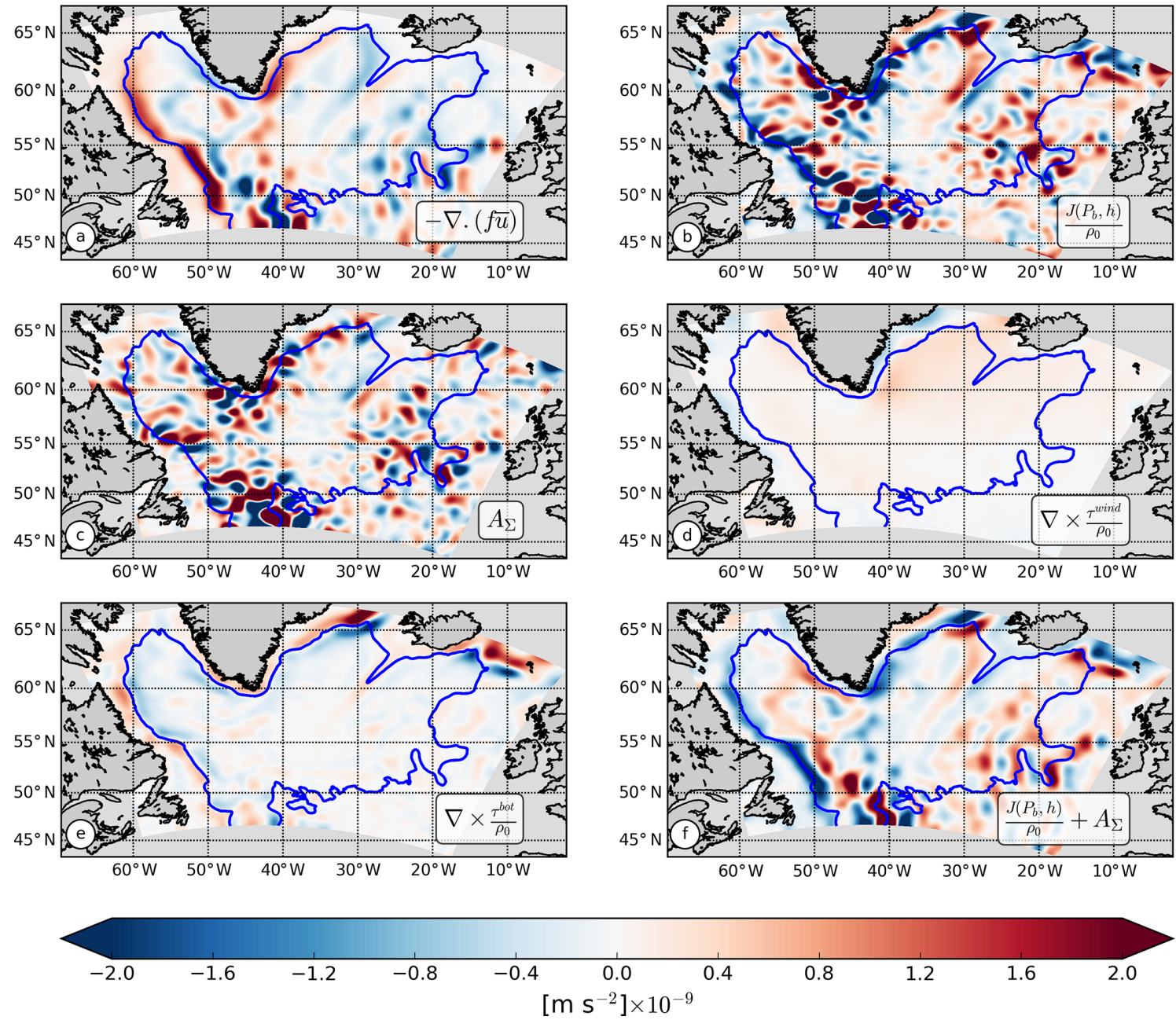

Figure 7. Time mean of the planetary vorticity (a), bottom pressure torque (b), nonlinear terms (c), wind stress curl (d), and bottom drag curl (e). As bottom pressure torque and nonlinear terms cancel each other, their sum is plotted in (f). The fields have been smoothed using a kernel of $1^{\circ}$ radius. The blue contour represents the limit of our shelf area and is the $-3 \mathrm{~Sv}$ barotropic streamline. 
$\frac{J\left(P_{\mathrm{b}}, h\right)}{\rho_{0}}=f u_{\mathrm{gb}} . \nabla h=-f w_{\mathrm{gb}}$, where $u_{\mathrm{gb}}$ is the horizontal geostrophic bottom flow.

The computation of the BPT in Spence et al. (2012) is performed by directly estimating the term $-f w_{\mathrm{b}}$, where $w_{\mathrm{b}}$ is the vertical velocity at the bottom. However, this estimation does not take into account the presence of an ageostrophic component of the velocity at the bottom, in particular the Ekman component of the velocity due to the bottom drag. The same computation in our model leads to the results in Fig. 8b, which are very different from the actual bottom pressure torque (Fig. 8a). It gives results quite similar to Spence et al. (2012) with positive signals - implying downwelling of bottom currents - over most of the boundaries of the gyre. But this downwelling is a result of the Ekman currents oriented to the left of the main bottom geostrophic currents, which are flowing with the shallower topography on their right around the gyre.

Following Mertz and Wright (1992) and Yeager (2015), the BPT can be further decomposed into

$$
\frac{J\left(P_{\mathrm{b}}, h\right)}{\rho_{0}}=f u_{\mathrm{gb}} \cdot \nabla h=\frac{f}{h} \overline{u_{\mathrm{g}}} \cdot \nabla h+h(\mathrm{JEBAR}),
$$

which illustrates that the bottom geostrophic currents that appear in the expression of BPT are the sum of a vertically averaged part and a baroclinic part directly related to the JEBAR term. The term $\frac{f}{h} \overline{u_{g}}$. $\nabla h$ highlights regions where the depthaveraged flow crosses isobaths and the $h$ (JEBAR) term for which the baroclinic effects play a role in decoupling the bottom flow from the barotropic flow through the geostrophic shear. In Fig. 8c the geostrophic velocity has been computed from the thermal wind balance referenced at the surface.

Along the continental slopes, on the western and northern part of the gyre, the flow is close to barotropic and the $\frac{f}{h} \overline{u_{\mathrm{g}}} \cdot \nabla H$ term has similar patterns and amplitudes as the BPT. This contrasts with results from Yeager (2015), who found that the $h$ (JEBAR) term was almost an order of magnitude larger than the BPT in these regions. However, over the southern and eastern part of the gyre, it is clear that the structure of the flow is much more baroclinic, and the $\frac{f}{h} \bar{u} \cdot \nabla h$ and $h$ (JEBAR) terms are both an order of magnitude larger than the BPT.

\section{Integrated vorticity balance for the shelf, slope, and interior of the gyre}

\subsection{Gyre integrated barotropic vorticity balances}

The maps of the barotropic vorticity terms, with various degrees of smoothing, can help identify the locally dominant terms but do not enable us to identify the important balances at the gyre scale. Spatial integrations are performed inside different gyre contours (Fig. 9) to better understand the main contributions to the circulation of the subpolar gyre.

We distinguish the shelf area from the gyre using a contour of barotropic stream function of $-3 \mathrm{~Sv}$. This contour is chosen because it corresponds to the largest possible closed contour of the barotropic stream function. We can check that the term $-\nabla \cdot(f \bar{u}) \approx-\beta V$ integrates to zero within such a contour (Fig. 9c). The shelf thus defined corresponds to an area with a mean depth of $290 \mathrm{~m}$ and extends from the south of Iceland to the Flemish Cap (blue area in Fig. 9b).

When integrated inside the $-3 \mathrm{~Sv}$ contour (which means excluding the shelf area; Fig. 9c), the main sources for the cyclonic circulation of the gyre are the wind and the BPT. They are balanced by the BDC. The wind input does not contribute much locally (Fig. 7) but becomes significant when integrated spatially over the whole gyre. The BPT is the major source of positive vorticity and helps the flow move cyclonically around the gyre. The BDC and NL terms act as sinks of vorticity, but the NL term is much smaller than the $\mathrm{BDC}$. The BDC is very intense where the current flows close to a steep topography, as in the case of the Labrador Current (LC) and the West Greenland Current.

When integrated over the whole gyre (Fig. 9a), the balance is slightly different. The wind is still a major contributor for the cyclonic circulation and the BDC still represents the major sink of vorticity. However, the NL term replaces the BPT as a source of cyclonic vorticity for the gyre. In this interpretation, both the wind and the NL term force the gyre cyclonically, while the BDC and BPT balance this input.

The difference between the two balances is highlighted by looking at the balance in the region between the two contours, which covers the upper slope and the shelf. It corresponds to a balance between BPT, NL, and bottom drag. The NL term is only significant around the Greenland shelf and is related to eddy interactions between the shelf and the open ocean. Otherwise, the vorticity is negative on the shelf, thus explaining the positive sign of the bottom drag. The main source of anticyclonic vorticity is related to the BPT. This balance is close to the one described in Csanady (1978) and Csanady (1997), and it evokes a buoyancy-driven flow in this area (Chapman et al., 1986; Chapman and Beardsley, 1989).

\subsection{Barotropic vorticity balance in the interior of the gyre}

It is clear from the patterns of the different terms of the barotropic vorticity balance that the local balances over the boundary currents are very different than what is happening in the interior of the gyre. The classical picture of a gyre interior (far from the boundaries) in a quasi-Sverdrup balance, which applies in the subtropical gyre, does not seem to apply anywhere in the SPG.

To better understand what drives the interior part of the subpolar gyre, we further divide the domain into an interior and a boundary part, as represented in Fig. 10. The two domains are defined using the $-3 \mathrm{~Sv}$ line as previously and the $3000 \mathrm{~m}$ isobath. What is between the $-3 \mathrm{~Sv}$ line and the $3000 \mathrm{~m}$ isobath is considered to be the slope region and the rest is considered to be the interior area. The choice of the 

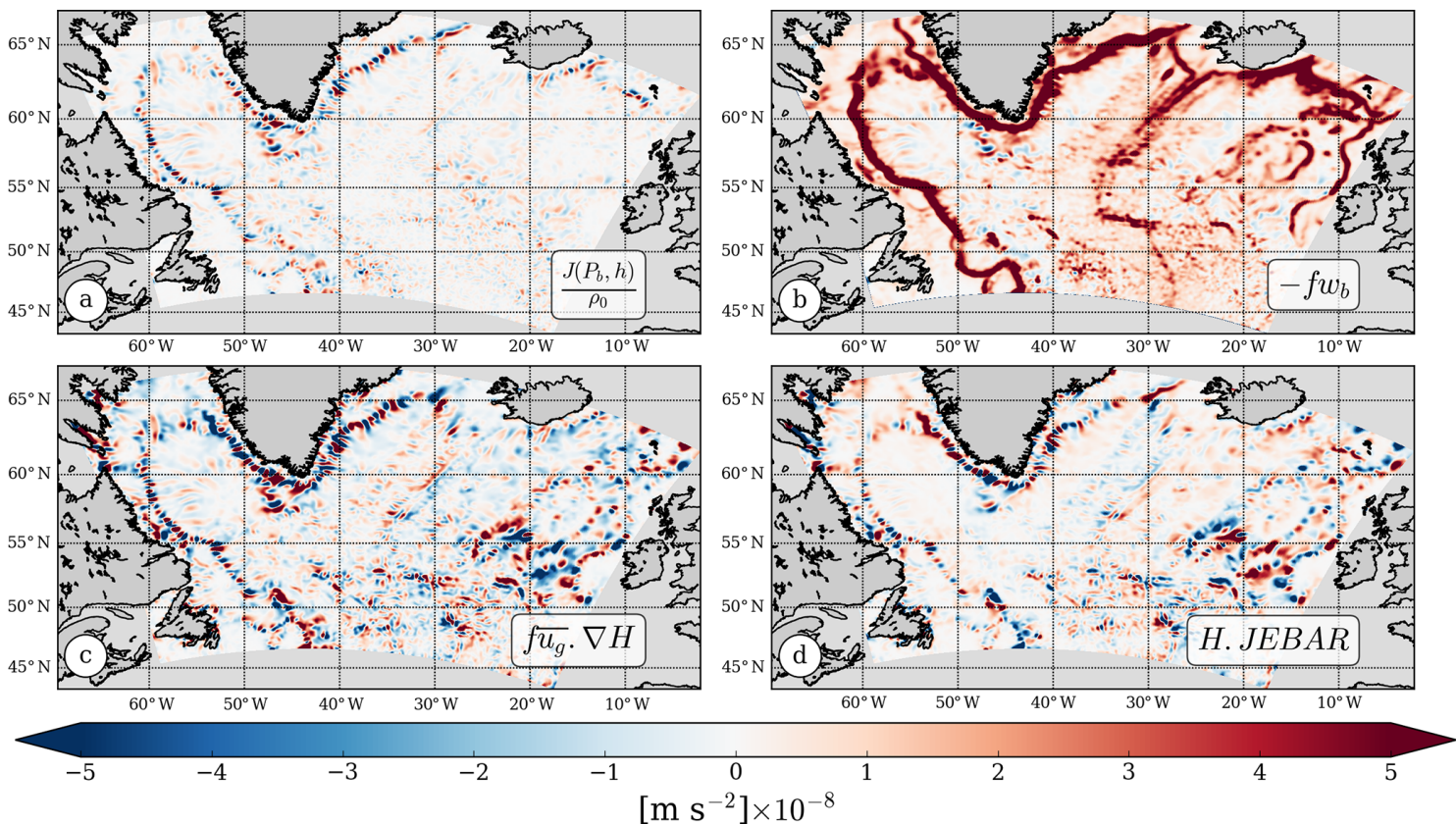

Figure 8. (a) Bottom pressure torque, (b) $-f w_{\mathrm{b}}$, (c) $\frac{f}{h} \overline{u_{\mathrm{g}}} \cdot \nabla H$, and (d) $H \cdot$ JEBAR for the $2 \mathrm{~km}$ North Atlantic subpolar gyre simulation smoothed with a $25 \mathrm{~km}$ Gaussian kernel.
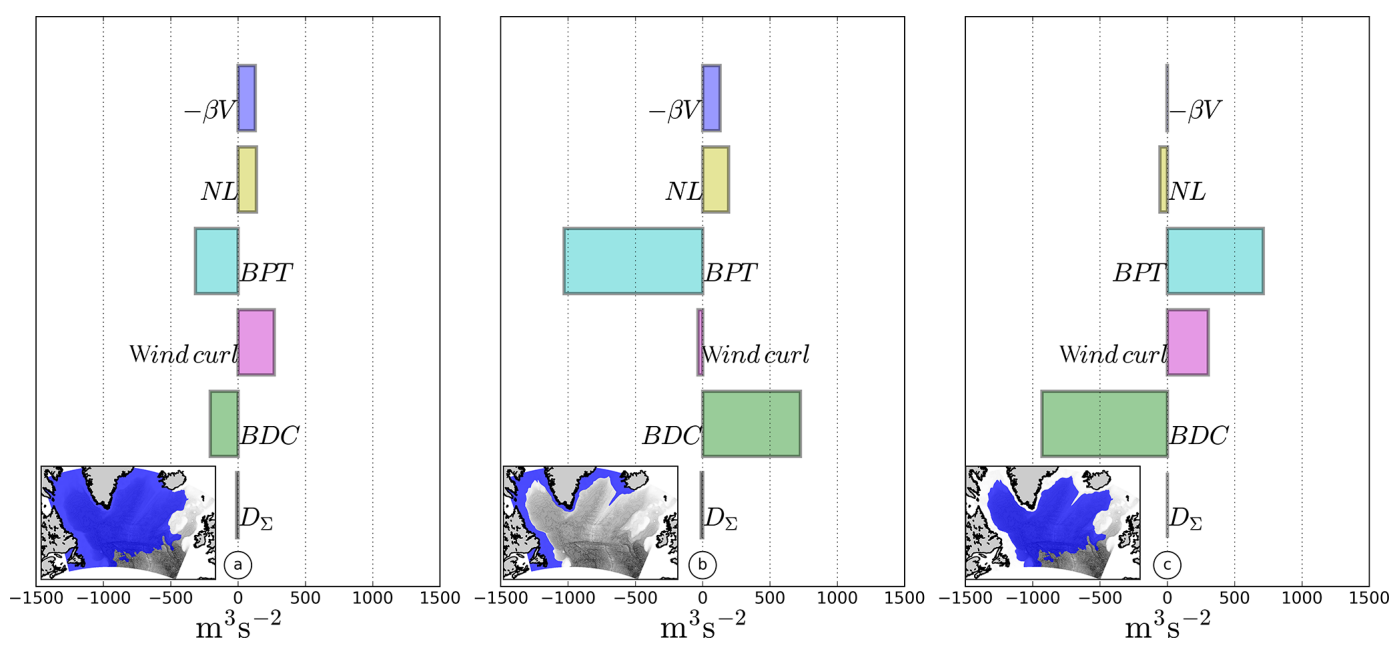

Figure 9. Integration of the barotropic vorticity terms over the SPG including or excluding the shelf area (panels a and c, respectively). The subpolar gyre area without the shelf corresponds to the $-3 \mathrm{~Sv}$ contour. The shelf balance is plotted in (b).

$3000 \mathrm{~m}$ isobath is somehow subjective, but the results are not sensitive to the choice of a specific isobath.

In the slope region, the main source of cyclonic vorticity is the BPT. The curl of the wind and the $\beta V$ are also positive. The strongly negative NL term indicates the advection of cyclonic vorticity outside this domain toward the shelf or the gyre interior.

In the interior, the NL term represents the major contribution to the cyclonic circulation. It is balanced by the BDC, the $\mathrm{BPT}$, and the $\beta V$ terms. Contributions from the $\mathrm{BDC}$ are of similar magnitude in the interior and the slope area. The wind input of vorticity is smaller than in the slope region, as the major wind source of vorticity is located near Greenland (Fig. 7d) and not uniformly distributed over the gyre. It confirms that the gyre interior is not in Sverdrup balance at the first order, which would imply a dominant balance between a negative $\beta V$ and a positive input from the curl of the wind stress, but is driven instead by nonlinear effects. The comparison between balances in the interior and slope regions indicates that the NL term helps to redistribute vorticity from the boundary toward the interior of the gyre. 

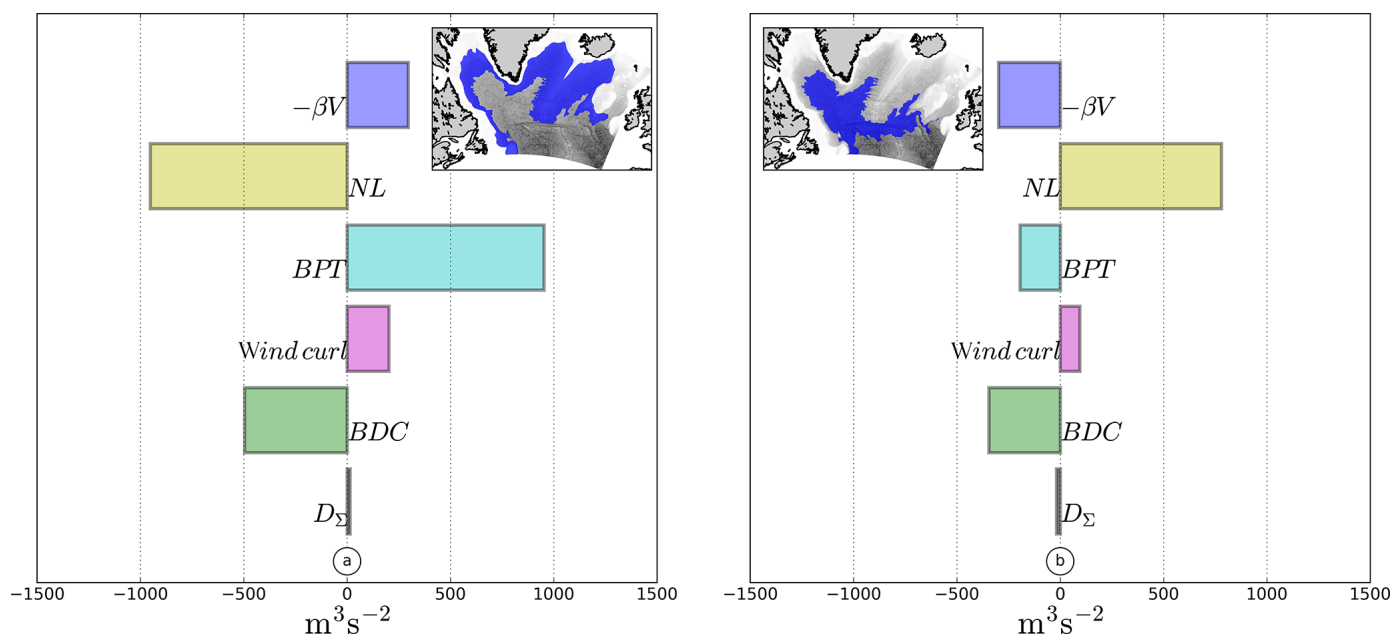

Figure 10. Integration of the barotropic vorticity terms in the slope area (a, defined between the barotropic stream function contour $-3 \mathrm{~Sv}$ and the $3000 \mathrm{~m}$ isobath) and interior (b).

\subsection{Balance in the slope area}

The main source of cyclonic vorticity inside the gyre is related to the NL term, which helps transfer the vorticity from the boundary toward the inside. But which boundary regions are the main contributors of vorticity to the interior?

Several types of regions can be identified by looking at the dominant terms in the barotropic vorticity balance (Fig. 11): the western boundary areas in cyan, which include the western Labrador Sea (WLS), eastern Greenland (EG), and eastern Reykjanes Ridge (ERR); the eastern boundary regions in yellow, which include western Greenland (WG), the western Reykjanes Ridge (WRR), and the eastern part of the Iceland Basin; and the northwest regions in green, which include the extension of the Denmark Strait and Iceland-Scotland overflows, as well as the northwestern part of the Labrador Sea.

The barotropic vorticity balance in the western boundary areas (cyan in Fig. 11) is close to the typical equilibrium of western boundary currents (WBCs) (Schoonover et al., 2016; Gula et al., 2015), with an equilibrium between the planetary vorticity and the BPT. For the WLS, the deviation from WBC dynamics is small and related to a bottom drag signal. We excluded the southern part near the Flemish Cap $\left(48^{\circ} \mathrm{N}\right.$, $46^{\circ} \mathrm{W}$ ) (not shown) where the dynamics are driven by a positive input of planetary vorticity and BPT balanced by the NL term. The case of the ERR is slightly different, with no net meridional transport in this area. The main input of vorticity is provided by the NL term, which is related to inertial effects from the current following the Iceland shelf. In this area the input of positive vorticity is mainly balanced by topography and the drag corresponding to a local dissipation of vorticity. From this we can infer that western boundary areas do not provide cyclonic vorticity to the gyre interior.

Three regions (green in Fig. 11) have in common a dominant contribution from the bottom drag. Vertical sections of the mean along-stream current (Fig. 12a, c, e) in these areas reveal a strongly intensified bottom current (especially near the Iceland shelf and the Denmark Strait). In comparison, WBCs have a more surface-intensified structure with reduced amplitudes near the bottom (Fig. 12b, d, f). In Fig. 12, vorticity balances are indicated. They differ from Fig. 11 because the integration is restricted to the boundary current, excluding recirculations. In Fig. 12a, c, and e the BPT amplitudes are reduced (and even change sign) compared to Fig. 11. This reflects the sensitivity of the vorticity balance to the location of the boundary on the continental slope. The $-3 \mathrm{~Sv}$ contour used in Fig. 11 does not coincide everywhere with the top of the continental slope used in Fig. 12.

The dynamics in the extension of the Denmark Strait and Iceland-Scotland overflows is a balance between the NL term and BDC, while in the northwestern Labrador Sea, the BDC balances the $\beta$ effect. As the BDC is the main sink of vorticity and only acts locally, no advection of positive vorticity toward the inside of the gyre can come from these locations.

In eastern boundary regions (yellow in Fig. 12), most of the cyclonic vorticity is provided by flow-topography interactions through the BPT and is balanced by the NL term. These regions are located where strong eddy activity is observed (Fig. 5), which might be responsible for the high amplitude of the NL term. This negative NL signal implies an export of positive vorticity toward either the shelf or the gyre interior.

\section{Characterization of the nonlinear term}

The NL term is locally important and balances the bottom pressure torque at small scales (Fig. 6). When integrated over the gyre it plays a role in exporting cyclonic vorticity from 


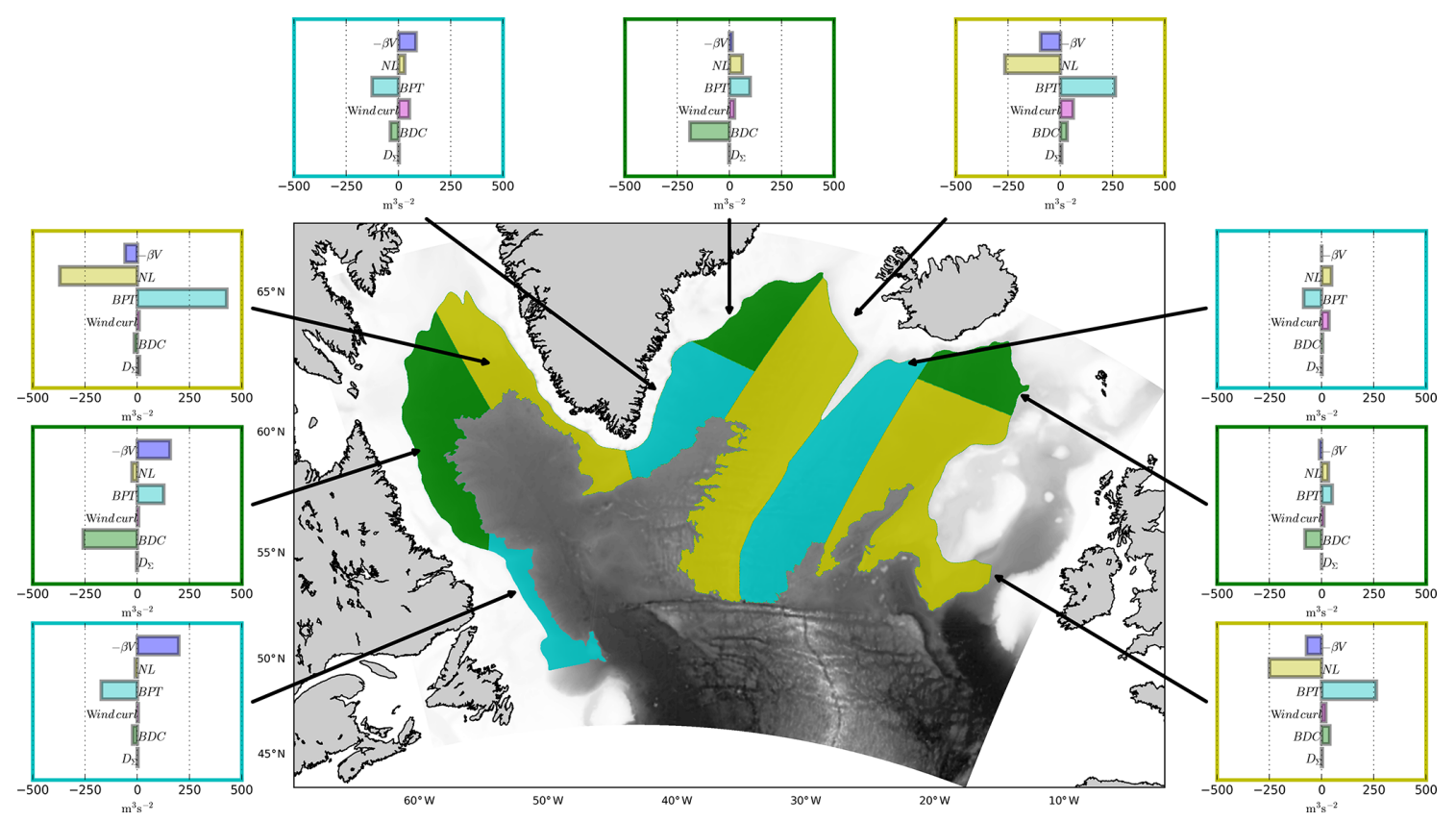

Figure 11. Barotropic vorticity balance integrated over different parts of the gyre along the slope.

the boundary toward the interior of the gyre. The NL term is, however, quite difficult to interpret as many processes are hidden inside the vertical and time integrals.

By decomposing the velocity into a barotropic and baroclinic part $\left(u=\bar{u}+u^{\prime}\right)$ the NL advection term can be written as

$$
A_{\Sigma}(u, v)=\underbrace{A(\bar{u}, \bar{v})}_{A_{\Sigma}^{\mathrm{bt}}}+\underbrace{A\left(u^{\prime}, v^{\prime}\right)}_{A_{\Sigma}^{\mathrm{bc}}},
$$

where the barotropic part can be written as $A(\bar{u}, \bar{v})=\bar{u} \Omega_{x}+$ $\bar{v} \Omega_{y}$ which is the advection of the barotropic vorticity by the barotropic flow.

We show these terms integrated over the slope area and interior (same as Fig. 10) in Fig. 13. Over the slope area, both terms are negative and contribute to exporting cyclonic vorticity. The barotropic part is much larger than its baroclinic counterpart and exports most of the vorticity, as can be expected from the barotropic structure of the currents over the slope. In the interior, both terms are positive, corresponding to an input of cyclonic vorticity for the interior (Fig. 13), but the NL term is evenly divided between its barotropic and baroclinic contributions. While defining our gyre interior with the $3000 \mathrm{~m}$ isobath and the $-3 \mathrm{~Sv}$ barotropic stream function (in the southeast boundary), we include a part of the subtropical gyre with the northwestern corner. The northwest corner provides about half of this baroclinic NL input, while the remaining part comes mostly from the southeastern boundary. The exchange of barotropic vorticity between the slope region and the interior is only due to the barotropic $\mathrm{NL}$ term.
It is also possible to decompose the NL term into a time mean and eddy part by writing $u=\langle u\rangle+u^{*}$, where $\langle\bullet\rangle$ is the time average and the star denotes the fluctuation part. By putting this in the nonlinear operator $A_{\Sigma}$ we have the following.

$$
\begin{aligned}
& A_{\Sigma}(u, v)=\underbrace{A_{\Sigma}(\langle u\rangle,\langle v\rangle)}_{A_{\Sigma}^{\text {mean }}}+\underbrace{A_{\Sigma}\left(u^{*}, v^{*}\right)}_{A_{\Sigma}^{\text {eddy }}} \\
& +\underbrace{\left\langle 2 \frac{\partial^{2} \overline{\langle v\rangle v^{*}}-\overline{\langle u\rangle u^{*}}}{\partial x y}+\frac{\partial^{2} \overline{\langle u\rangle v^{*}}+\overline{\langle v\rangle u^{*}}}{\partial x x}-\frac{\partial^{2} \overline{\langle u\rangle v^{*}}+\overline{\langle v\rangle u^{*}}}{\partial y y}\right\rangle}_{\varepsilon}
\end{aligned}
$$

The $\varepsilon$ part is the residue of the cross-product, and its value is negligible compared to both the mean and eddy parts.

When integrated over the slope area (Fig. 13), the eddy component dominates over the mean one. In the interior area, the supply of barotropic vorticity is also mainly due to the eddy component, but the mean component contributes about a third of the total. Almost all of this mean signal is coming from the northwest corner, consistent with Wang et al. (2017), while the eddy part is dominant over the rest of the interior.

We can identify several processes providing cyclonic barotropic vorticity to the subpolar gyre. The most important is the eddy contribution coming from the boundary area that is associated with a barotropic contribution. Barotropic vorticity is also provided through a mean baroclinic signal in the NWC region. Our definition of the subpolar gyre, based on a barotropic stream function contour, includes a part of the 

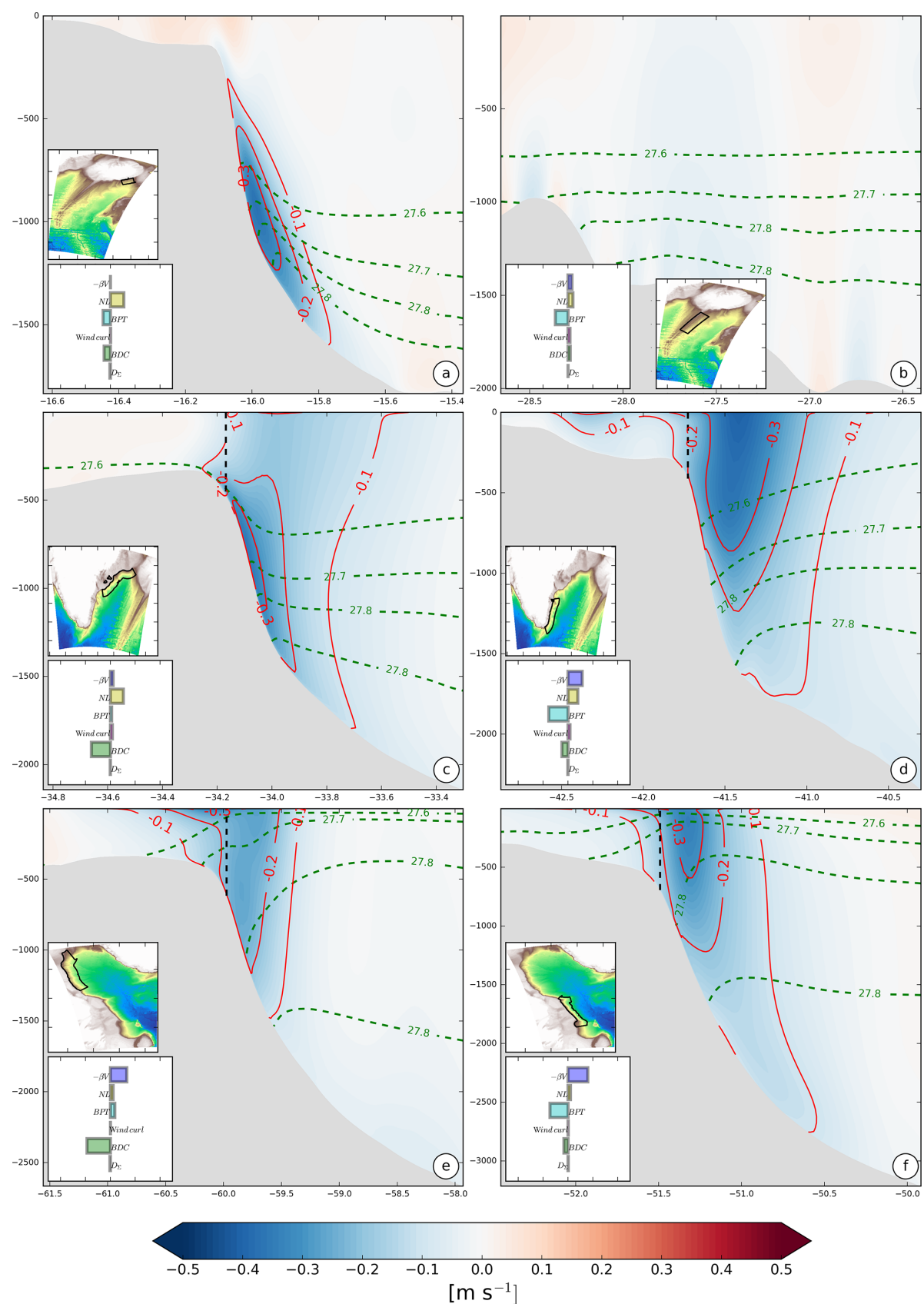

Figure 12. Vertical section of the mean along-stream current near the Iceland shelf (a), eastern Reykjanes Ridge (b), Denmark Strait (c), eastern Greenland (d), northern Labrador Current (e), and southern Labrador Current (f). Red solid lines and green dashed lines are velocity and surface-referenced potential density contours, respectively, while the black dashed line is the limit of integration near the shelf. The black contour on the topography map represents the area on which barotropic vorticity terms are integrated.

NWC, which is a complex transition region between the subtropical and the subpolar gyre. In comparison, in the lowerresolution simulation (not shown), most of the vorticity is advected inside the gyre by mean barotropic processes, but the amplitude of the NL term is cut by half.

\section{$7 \quad$ Summary and conclusions}

We have studied the dynamics of the North Atlantic subpolar gyre in a numerical model with, for the first time, terrainfollowing coordinates and a mesoscale-resolving resolution $(\Delta x \approx 2 \mathrm{~km})$. The combination of the high resolution with $\sigma$ levels allows us to better resolve the effects of the mesoscale turbulence and the complex bottom topography. The repre- 


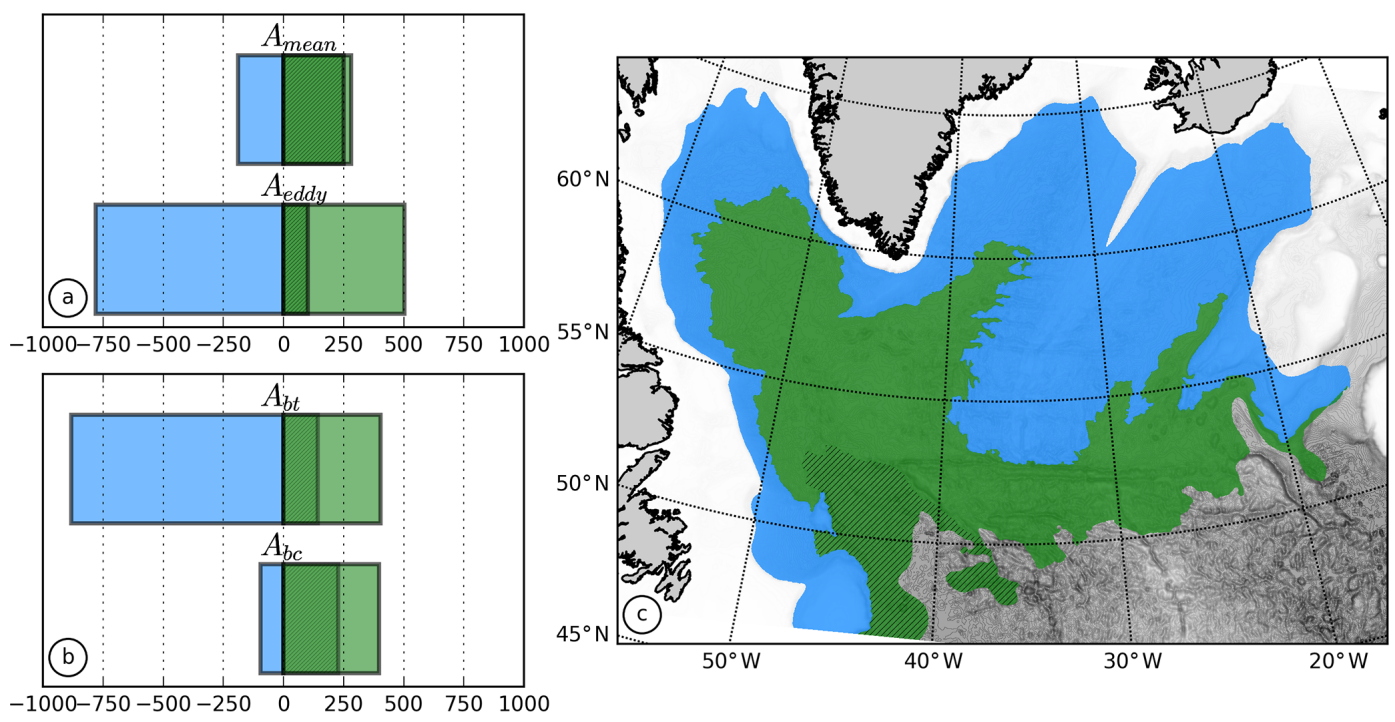

Figure 13. Integration of the nonlinear term in the slope (c, blue) and interior area (c, green) for the mean eddy decomposition (a) and the barotropic-baroclinic decomposition (b). The hatches are the contribution from the northwestern corner.

sentation of the mean currents and their variability is improved compared to previous simulations with coarser resolution. In particular, the simulations produce realistic levels of mesoscale turbulence at the surface and in the interior, as seen from comparisons of eddy potential and kinetic energy with observations from Argo floats and surface drifters.

The role of topography is essential in the SPG. This impact is reflected in the barotropic vorticity balance of the gyre through the bottom pressure torque. The bottom pressure torque is sometimes interpreted as the effect of the vortex stretching due to the bottom flow over topography, as expected for a predominantly geostrophic flow. However, we show here that the ageostrophic effects, in particular due to the viscous bottom drag, are predominant at the bottom and the BPT cannot be estimated from the bottom vertical velocity.

Barotropic vorticity balances are opposite in the shelf region compared to the interior of the gyre. The main balance in the shelf region is between a negative bottom pressure torque and a positive bottom drag, which is typical of a buoyancy-driven current. Inside the gyre, the inputs of positive vorticity from the BPT and the wind curl are balanced by the bottom drag curl. The important role played by the bottom drag and the weak role played by the viscous torque, compared to other models, are related to the choice of $\sigma$-level coordinates and high horizontal resolution.

The bottom pressure torque has a large amplitude where boundary currents flow along the steep continental slope. It is the main term balancing the meridional transport of water in western boundary currents, except for some regions with dense water overflows where the bottom drag curl can become predominant. On the eastern (northward-flowing) boundary currents, the strong input of positive vorticity by the bottom pressure torque is balanced by the nonlinear term. The nonlinearities, which are essentially due to the eddying activity, allow for the advection of the positive vorticity from the boundary toward the interior of the gyre. A positive input of vorticity is also related to the presence of the northwestern corner, mostly through time-mean baroclinic fluxes.

The nonlinear term is the main forcing for the interior part of the gyre, overcoming the effects of the wind curl and bottom pressure torque. This puts forward the failure of the classical Sverdrup balance or even a topographic Sverdrup balance in the interior of the subpolar gyre, emphasizing the importance of inertial effects to obtain a more realistic subpolar gyre circulation.

Data availability. The ANDRO and NOAA datasets are available online at https://www.seanoe.org/data/00360/47077/ (last access: March 2020), https://doi.org/10.17882/47077 (Ollitrault et al., 2019); https://doi.org/10.1016/j.dsr.2017.04.009 (Laurindo et al., 2017), and https://www.aoml.noaa.gov/phod/gdp/interpolated/data/ subset.php (last access: March 2020) (Atlantic Oceanographic and Meteorological Laboratory of the National Oceanic and Atmospheric Administration, 2020).

Author contributions. MLC designed the setup and carried out the experiment. MLC and JG analyzed the output of the simulation. All authors participated in the writing and editing of the article.

Competing interests. The authors declare that they have no conflict of interest. 
Acknowledgements. Jonathan Gula is supported by UBO and Anne-Marie Tréguier by CNRS. Simulations were performed using HPC resources from GENCI-TGCC (grant 2018-A0050107638) and from DATARMOR of "Pôle de Calcul Intensif pour la Mer" at Ifremer, Brest, France. Model outputs are available upon request. We are grateful for comments provided by two anonymous referees that helped to improve the paper.

Financial support. This research has been supported by UBO and Région Bretagne through ISblue, the Interdisciplinary graduate school for the blue planet (project no. ANR-17-EURE-0015).

Review statement. This paper was edited by Matthew Hecht and reviewed by two anonymous referees.

\section{References}

Beckmann, A. and Haidvogel, D. B.: Numerical Simulation of Flow around a Tall Isolated Seamount. Part I: Problem Formulation and Model Accuracy, J. Phys. Oceanogr., 23, 1736-1753, https://doi.org/10.1175/15200485(1993)023<1736:NSOFAA >2.0.CO;2, 1993.

Bower, A. S.: Interannual Variability in the Pathways of the North Atlantic Current over the Mid-Atlantic Ridge and the Impact of Topography, J. Phys. Oceanogr., 38, 104-120, https://doi.org/10.1175/2007JPO3686.1, 2008.

Bower, A. S., Le Cann, B., Rossby, T., Zenk, W., Gould, J., Speer, K., Richardson, P. L., Prater, M. D., and Zhang, H.-M.: Directly measured mid-depth circulation in the northeastern North Atlantic Ocean, Nature, 419, 603-607, https://doi.org/10.1038/nature01078, 2002.

Brandt, P.: Seasonal to interannual variability of the eddy field in the Labrador Sea from satellite altimetry, J. Geophys. Res., 109, C02028, https://doi.org/10.1029/2002JC001551, 2004.

Bryan, F. O., Hecht, M. W., and Smith, R. D.: Resolution convergence and sensitivity studies with North Atlantic circulation models. Part I: The western boundary current system, Ocean Model., 16, 141-159, https://doi.org/10.1016/j.ocemod.2006.08.005, 2007.

Carton, J. A. and Giese, B. S.: A Reanalysis of Ocean Climate Using Simple Ocean Data Assimilation (SODA), Mon. Weather Rev., 136, 2999-3017, https://doi.org/10.1175/2007MWR1978.1, 2008.

Chapman, D. C. and Beardsley, R. C.: On the Origin of Shelf Water in the Middle Atlantic Bight, J. Phys. Oceanogr., $\quad 19, \quad 384-391, \quad$ https://doi.org/10.1175/15200485(1989)019<0384:OTOOSW>2.0.CO;2, 1989.

Chapman, D. C., Barth, J. A., Beardsley, R. C., and Fairbanks, R. G.: On the Continuity of Mean Flow between the Scotian Shelf and the Middle Atlantic Bight, J. Phys. Oceanogr., 16, 758-772, https://doi.org/10.1175/15200485(1986)016<0758:OTCOMF>2.0.CO;2, 1986.

Chelton, D. B., Deszoeke, R. A., Schlax, M. G., Naggar, K. E., and Siwertz, N.: Geographical Variability of the First Baroclinic Rossby Radius of Deformation, J.
Phys. Oceanogr., 28, 433-460, https://doi.org/10.1175/15200485(1998)028<0433:GVOTFB>2.0.CO;2, 1998.

Csanady, G. T.: The Arrested Topographic Wave, J. Phys. Oceanogr., 8, 47-62, https://doi.org/10.1175/15200485(1978)008<0047:TATW>2.0.CO;2, 1978.

Csanady, G.: On the theories that underlie our understanding of continental shelf circulation, J. Oceanogr., 53, 207-229, 1997.

Cuny, J., Rhines, P. B., Niiler, P. P., and Bacon, S.: Labrador Sea Boundary Currents and the Fate of the Irminger Sea Water, J. Phys. Oceanogr., 32, 627-647, https://doi.org/10.1175/15200485(2002)032<0627:LSBCAT>2.0.CO;2, 2002.

Danek, C.: Effects of high resolution and spinup time on modeled North Atlantic, J. Phys. Oceanogr., 49, 1159-1181, https://doi.org/10.1175/JPO-D-18-0141.1, 2019.

Daniault, N., Mercier, H., Lherminier, P., Sarafanov, A., Falina, A., Zunino, P., Pérez, F. F., Ríos, A. F., Ferron, B., Huck, T., Thierry, V., and Gladyshev, S.: The northern North Atlantic Ocean mean circulation in the early 21 st century, Prog. Oceanogr., 146, 142158, https://doi.org/10.1016/j.pocean.2016.06.007, 2016.

Debreu, L., Marchesiello, P., Penven, P., and Cambon, G.: Twoway nesting in split-explicit ocean models: Algorithms, implementation and validation, Ocean Model., 49-50, 1-21, https://doi.org/10.1016/j.ocemod.2012.03.003, 2012.

de Jong, M. F., Bower, A. S., and Furey, H. H.: Seasonal and Interannual Variations of Irminger Ring Formation and BoundaryInterior Heat Exchange in FLAME, J. Phys. Oceanogr., 46, 1717-1734, https://doi.org/10.1175/JPO-D-15-0124.1, 2016.

Deshayes, J., Frankignoul, C., and Drange, H.: Formation and export of deep water in the Labrador and Irminger Seas in a GCM, Deep-Sea Res. Pt. I, 54, 510-532, https://doi.org/10.1016/j.dsr.2006.12.014, 2007.

Drews, A. and Greatbatch, R. J.: Evolution of the Atlantic Multidecadal Variability in a Model with an Improved North Atlantic Current, J. Climate, 30, 5491-5512, https://doi.org/10.1175/JCLI-D-16-0790.1, 2017.

Drews, A., Greatbatch, R. J., Ding, H., Latif, M., and Park, W.: The use of a flow field correction technique for alleviating the North Atlantic cold bias with application to the Kiel Climate Model, Ocean Dynam., 65, 1079-1093, https://doi.org/10.1007/s10236015-0853-7, 2015.

Ezer, T.: Revisiting the problem of the Gulf Stream separation: on the representation of topography in ocean models with different types of vertical grids, Ocean Model., 104, 15-27, https://doi.org/10.1016/j.ocemod.2016.05.008, 2016.

Ezer, T. and Mellor, G. L.: A generalized coordinate ocean model and a comparison of the bottom boundary layer dynamics in terrain-following and in z-level grids, Ocean Model., 6, 379-403, https://doi.org/10.1016/S1463-5003(03)00026-X, 2004.

Fischer, J., Karstensen, J., Oltmanns, M., and Schmidtko, S.: Mean circulation and EKE distribution in the Labrador Sea Water level of the subpolar North Atlantic, Ocean Sci., 14, 1167-1183, https://doi.org/10.5194/os-14-1167-2018, 2018.

Fischer, J. R., Schott, F. A., and Dengler, M.: Boundary Circulation at the Exit of the Labrador Sea, J. Phys. Oceanogr., 34, 23, 2004.

Flatau, M. K., Talley, L., and Niiler, P. P.: The North Atlantic Oscillation, Surface Current Velocities, and SST Changes in the Subpolar North Atlantic, J. Climate, 16, 2355-2369, https://doi.org/10.1175/2787.1, 2003. 
Greatbatch, R. J., Fanning, A. F., Goulding, A. D., and Levitus, S.: A diagnosis of interpentadal circulation changes in the North Atlantic, J. Geophys. Res., 96, 22009, https://doi.org/10.1029/91JC02423, 1991.

Griffies, S. M., Biastoch, A., Böning, C., Bryan, F., Danabasoglu, G., Chassignet, E. P., England, M. H., Gerdes, R., Haak, H., Hallberg, R. W., Hazeleger, W., Jungclaus, J., Large, W. G., Madec, G., Pirani, A., Samuels, B. L., Scheinert, M., Gupta, A. S., Severijns, C. A., Simmons, H. L., Treguier, A. M., Winton, M., Yeager, S., and Yin, J.: Coordinated Ocean-ice Reference Experiments (COREs), Ocean Model., 26, 1-46, https://doi.org/10.1016/j.ocemod.2008.08.007, 2009.

Gula, J., Molemaker, M. J., and McWilliams, J. C.: Gulf Stream Dynamics along the Southeastern U.S. Seaboard, J. Phys. Oceanogr., 45, 690-715, https://doi.org/10.1175/JPO-D14-0154.1, 2015.

Hansen, B., Húsgarð Larsen, K. M., Hátún, H., and Østerhus, S.: A stable Faroe Bank Channel overflow 1995-2015, Ocean Sci., 12, 1205-1220, https://doi.org/10.5194/os-12-1205-2016, 2016.

Hecht, M. W. and Smith, R. D.: Towards a Physical Understanding of the North Atlantic: A Review of Model Studies in an Eddying Regime, American Geophysical Union (AGU), Ocean Modeling in an Edddying Regime, 177, 213-239, https://doi.org/10.1029/177GM15, 2008.

Holliday, N. P., Bacon, S., Allen, J., and McDonagh, E. L.: Circulation and Transport in the Western Boundary Currents at Cape Farewell, Greenland, J. Phys. Oceanogr., 39, 1854-1870, https://doi.org/10.1175/2009JPO4160.1, 2009.

Hughes, C. W.: A theoretical reason to expect inviscid western boundary currents in realistic oceans, Ocean Model., 2, 73-83, https://doi.org/10.1016/S1463-5003(00)00011-1, 2000.

Hughes, C. W. and De Cuevas, B. A.: Why Western Boundary Currents in Realistic Oceans are Inviscid: A Link between Form Stress and Bottom Pressure Torques, J. Phys. Oceanogr., 31, 2871-2885, https://doi.org/10.1175/15200485(2001)031<2871:WWBCIR>2.0.CO;2, 2001.

Jackson, L., Hughes, C. W., and Williams, R. G.: Topographic Control of Basin and Channel Flows: The Role of Bottom Pressure Torques and Friction, J. Phys. Oceanogr., 36, 1786-1805, https://doi.org/10.1175/JPO2936.1, 2006.

Kanzow, T. and Zenk, W.: Structure and transport of the Iceland Scotland Overflow plume along the Reykjanes Ridge in the Iceland Basin, Deep-Sea Res. Pt. I, 86, 82-93, https://doi.org/10.1016/j.dsr.2013.11.003, 2014.

Käse, R. H., Biastoch, A., and Stammer, D. B.: On the mid-depth circulation in the Labrador and Irminger Seas, Geophys. Res. Lett., 28, 3433-3436, https://doi.org/10.1029/2001GL013192, 2001.

Laurindo, L. C., Mariano, A. J., and Lumpkin, R.: An improved near-surface velocity climatology for the global ocean from drifter observations, Deep-Sea Res. Pt. I, 124, 73-92, https://doi.org/10.1016/j.dsr.2017.04.009, 2017.

Lavender, K. L., Davis, R. E., and Owens, W. B.: Mid-depth recirculation observed in the interior Labrador and Irminger seas by direct velocity measurements, Nature, 407, 66-69, https://doi.org/10.1038/35024048, 2000.

Lavender, K. L., Brechner Owens, W., and Davis, R. E.: The middepth circulation of the subpolar North Atlantic Ocean as mea- sured by subsurface floats, Deep-Sea Res. Pt. I, 52, 767-785, https://doi.org/10.1016/j.dsr.2004.12.007, 2005.

Lazier, J. R.: Observations in the Nortwest Corner of the North Atlantic Current, J. Phys. Oceanogr., 24, 1449-1463, https://doi.org/10.1175/15200485(1994)024<1449:OITNCO>2.0.CO;2, 1994.

Lebedev, K. V., Yoshinari, H., Maximenko, N. A., and Hacker, P. W.: YoMaHa'07: Velocity data assessed from trajectories of Argo floats at parking level and at the sea surface, Technical report, IPRC Tech. Note 4 (2), 16 pp., https://doi.org/10.13140/RG.2.2.12820.71041, 2007.

Le Bras, I. A.-A., Sonnewald, M., and Toole, J. M.: A barotropic vorticity budget for the subtropical North Atlantic based on observations, J. Phys. Oceanogr., 49, 2781-2797, https://doi.org/10.1175/JPO-D-19-0111.1, 2019.

Le Corre, M., Gula, J., Smilenova, A., and Houpert, L.: On the dynamics of a deep quasi-permanent anticylonic eddy in the Rockall Trough, p. 12, Association Français de Mécanique, Brest, France, 2019.

Lemarié, F., Kurian, J., Shchepetkin, A. F., Jeroen Molemaker, M., Colas, F., and McWilliams, J. C.: Are there inescapable issues prohibiting the use of terrain-following coordinates in climate models?, Ocean Model., 42, 57-79, https://doi.org/10.1016/j.ocemod.2011.11.007, 2012.

Lorenz, E. N.: Available Potential Energy and the Maintenance of the General Circulation, Tellus, 7, 157-167, https://doi.org/10.1111/j.2153-3490.1955.tb01148.x, 1955.

Luyten, J., Stommel, H., and Wunsch, C.: A Diagnostic Study of the Northern Atlantic Subpolar Gyre, J. Phys. Oceanogr., 15, 1344-1348, https://doi.org/10.1175/15200485(1985)015<1344:ADSOTN>2.0.CO;2, 1985.

Marzocchi, A.: The North Atlantic subpolar circulation in an eddyresolving global ocean model, J. Marine Syst., 142, 126-143, https://doi.org/10.1016/j.jmarsys.2014.10.007, 2015.

McWilliams, J. C.: The Nature and Consequences of Oceanic Eddies, in: Ocean Modeling in an Eddying Regime, edited by: Hecht, M. and Hasumi, H., AGU, Washington, D.C., https://doi.org/10.1029/177GM03, 2008.

Mertz, G. and Wright, D. G.: Interpretations of the JEBAR Term, J. Phys. Oceanogr., 22, 301-305, https://doi.org/10.1175/15200485(1992)022<0301:IOTJT>2.0.CO;2, 1992.

Munk, W. H.: On the wind-driven ocean circulation, J. Meteorol., 7, 80-93, https://doi.org/10.1175/15200469(1950)007<0080:OTWDOC>2.0.CO;2, 1950.

Ollitrault, M. and Rannou, J.-P.: ANDRO: An Argo-Based Deep Displacement Dataset, J. Atmos. Ocean. Tech., 30, 759-788, https://doi.org/10.1175/JTECH-D-12-00073.1, 2013.

Ollitrault, M., Rannou, P., Brion, E., Cabanes, C., Piron, A., Reverdin, G., and Kolodziejczyk, N.: ANDRO: An Argo-based deep displacement dataset, SEANOE, https://doi.org/10.17882/47077, 2019.

Pacanowski, R. C. and Gnanadesikan, A.: Transient Response in a Z-Level Ocean Model That Resolves Topography with Partial Cells, Mon. Weather Rev., 126, 3248-3270, https://doi.org/10.1175/15200493(1998)126<3248:TRIAZL>2.0.CO;2, 1998.

Paillet, J. and Mercier, H.: An inverse model of the eastern North Atlantic general circulation and thermocline ventilation, Deep- 
Sea Res. Pt. I, 44, 1293-1328, https://doi.org/10.1016/S09670637(97)00019-8, 1997.

Palter, J. B., Caron, C.-A., Law, K. L., Willis, J. K., Trossman, D. S., Yashayaev, I. M., and Gilbert, D.: Variability of the directly observed, middepth subpolar North Atlantic circulation, Geophys. Res. Lett., 43, 2700-2708, https://doi.org/10.1002/2015GL067235, 2016.

Petit, T., Mercier, H., and Thierry, V.: First Direct Estimates of Volume and Water Mass Transports Across the Reykjanes Ridge, J. Geophys. Res.-Oceans, 123, 6703-6719, https://doi.org/10.1029/2018JC013999, 2018.

Renault, L., Molemaker, M. J., Gula, J., Masson, S., and McWilliams, J. C.: Control and Stabilization of the Gulf Stream by Oceanic Current Interaction with the Atmosphere, J. Phys. Oceanogr., 46, 3439-3453, https://doi.org/10.1175/JPO-D-160115.1, 2016.

Reverdin, G.: North Atlantic Ocean surface currents, J. Geophys. Res., 108, 3002, https://doi.org/10.1029/2001JC001020, 2003.

Rossby, T. and Flagg, C. N.: Direct measurement of volume flux in the Faroe-Shetland Channel and over the Iceland-Faroe Ridge: DIRECT MEASUREMENT OF CURRENTS, Geophys. Res. Lett., 39, L07602, https://doi.org/10.1029/2012GL051269, 2012.

Roullet, G., Capet, X., and Maze, G.: Global interior eddy available potential energy diagnosed from Argo floats, Geophys. Res. Lett., 41, 1651-1656, https://doi.org/10.1002/2013GL059004, 2014.

Sandwell, D. T. and Smith, W. H. F.: Marine gravity anomaly from Geosat and ERS 1 satellite altimetry, J. Geophys. Res.-Sol. Ea., 102, 10039-10054, https://doi.org/10.1029/96JB03223, 1997.

Schoonover, J., Dewar, W., Wienders, N., Gula, J., McWilliams, J. C., Molemaker, M. J., Bates, S. C., Danabasoglu, G., and Yeager, S.: North Atlantic Barotropic Vorticity Balances in Numerical Models, J. Phys. Oceanogr., 46, 289-303, https://doi.org/10.1175/JPO-D-15-0133.1, 2016.

Shchepetkin, A. F. and McWilliams, J. C.: The regional oceanic modeling system (ROMS): a split-explicit, free-surface, topography-following-coordinate oceanic model, Ocean Model., 9, 347-404, https://doi.org/10.1016/j.ocemod.2004.08.002, 2005.

Shchepetkin, A. F. and McWilliams, J. C.: Computational Kernel Algorithms for Fine-Scale, Multiprocess, Longtime Oceanic Simulations, in: Handbook of Numerical Analysis, Elsevier, 14, 121-183, https://doi.org/10.1016/S1570-8659(08)01202-0, 2009.

Shchepetkin, A. F. and McWilliams, J. C.: Accurate Boussinesq oceanic modeling with a practical, "Stiffened" Equation of State, Ocean Model., 38, 41-70, https://doi.org/10.1016/j.ocemod.2011.01.010, 2011.
Smilenova, A., Gula, J., Le Corre, M., and Houpert, L.: On the vertical structure and generation mechanism of a deep anticyclonic vortex in the central Rockall Trough, northeast North Atlantic, J. Geophys. Res.-Oceans, in review, 2020.

Sonnewald, M., Wunsch, C., and Heimbach, P.: Unsupervised Learning Reveals Geography of Global Ocean Dynamical Regions, Earth Space Sci., https://doi.org/10.1029/2018EA000519, 2019.

Spall, M. A. and Pickart, R. S.: Wind-Driven Recirculations and Exchange in the Labrador and Irminger Seas, J. Phys. Oceanogr., 33, 1829-1845, https://doi.org/10.1175/2384.1, 2003.

Spence, P., Saenko, O. A., Sijp, W., and England, M.: The Role of Bottom Pressure Torques on the Interior Pathways of North Atlantic Deep Water, J. Phys. Oceanogr., 42, 110-125, https://doi.org/10.1175/2011JPO4584.1, 2012.

Stommel, H.: The westward intensification of wind-driven ocean currents, Transactions, American Geophysical Union, 29, 202, https://doi.org/10.1029/TR029i002p00202, 1948.

Thomas, M. D., De Boer, A. M., Johnson, H. L., and Stevens, D. P.: Spatial and Temporal Scales of Sverdrup Balance, J. Phys. Oceanogr., 44, 2644-2660, https://doi.org/10.1175/JPOD-13-0192.1, 2014.

Treguier, A. M., Theetten, S., Chassignet, E. P., Penduff, T., Smith, R., Talley, L., Beismann, J. O., and Böning, C.: The North Atlantic Subpolar Gyre in Four High-Resolution Models, J. Phys. Oceanogr., 35, 757-774, https://doi.org/10.1175/JPO2720.1, 2005.

Umlauf, L. and Burchard, H.: A generic length-scale equation for geophysical turbulence models, J. Marine Res., 61, 235-265, https://doi.org/10.1357/002224003322005087, 2003.

Van Aken, H. M.: Mean currents and current variability in the iceland basin, Netherlands J. Sea Res., 33, 135-145, https://doi.org/10.1016/0077-7579(95)90001-2, 1995.

Wang, Y., Claus, M., Greatbatch, R. J., and Sheng, J.: Decomposition of the Mean Barotropic Transport in a High-Resolution Model of the North Atlantic Ocean, Geophys. Res. Lett., 44, 11537-11546, https://doi.org/10.1002/2017GL074825, 2017.

Wunsch, C.: Is the North Atlantic in Sverdrup Balance?, J. Phys. Oceanogr., 15, 1876-1880, https://doi.org/10.1175/15200485(1985)015<1876:ITNAIS>2.0.CO;2, 1985.

Yeager, S.: Topographic Coupling of the Atlantic Overturning and Gyre Circulations, J. Phys. Oceanogr., 45, 1258-1284, https://doi.org/10.1175/JPO-D-14-0100.1, 2015.

Zhao, J., Bower, A., Yang, J., Lin, X., and Penny Holliday, N.: Meridional heat transport variability induced by mesoscale processes in the subpolar North Atlantic, Nat. Commun., 9, 1124, https://doi.org/10.1038/s41467-018-03134-x, 2018. 